\title{
Nrf2 as a Master Redox Switch in Turning on the Cellular Signaling Involved in the Induction of Cytoprotective Genes by Some Chemopreventive Phytochemicals
}

Author

Affiliation
Young-Joon Surh, Joydeb Kumar Kundu, Hye-Kyung Na

National Research Laboratory of Molecular Carcinogenesis and Chemoprevention, College of Pharmacy, Seoul National University, Seoul, South Korea
Key words

- chemoprevention

- Nrf2

dietary phytochemicals

- redox switch

- cellular signaling

cytoprotective genes

received June 1, 2008 revised July 22, 2008

accepted August 5, 2008

Bibliography

DOI 10.1055/s-0028-1088302

Planta Med 2008; 74: 1526-

1539

(c) Georg Thieme Verlag KG

Stuttgart · New York

Published online October 20,

2008

ISSN 0032-0943

Correspondence

Professor Young-Joon Surh

College of Pharmacy

Seoul National University,

Shillim-dong

Kwanak-gu

Seoul 151-742

Korea

Tel.: +82-2-880-7845

Fax: +82-2-874-9775

surh@plaza.snu.ac.kr

\section{Abstract \\ $\nabla$}

A wide array of dietary phytochemicals have been reported to induce the expression of enzymes involved in both cellular antioxidant defenses and elimination/inactivation of electrophilic carcinogens. Induction of such cytoprotective enzymes by edible phytochemicals largely accounts for their cancer chemopreventive and chemoprotective activities. Nuclear factor-erythroid-2-related factor 2 (Nrf2) plays a crucial role in the coordinated induction of those genes encoding many stress-responsive and cytoptotective enzymes and related proteins. These include $\mathrm{NAD}(\mathrm{P}) \mathrm{H}$ :quinone oxidoreductase-1, heme oxygenase-1, glutamate cysteine ligase, glutathione $S$-transferase, glutathione peroxidase, thioredoxin, etc. In resting cells, Nrf2 is sequestered in the cytoplasm as an inactive complex with the repressor Kelchlike ECH-associated protein 1 (Keap1). The release of Nrf2 from its repressor is most likely to be achieved by alterations in the structure of Keap1. Keap1 contains several reactive cysteine residues that function as sensors of cellular redox changes. Oxidation or covalent modification of some of these critical cysteine thiols would stabi-

\section{Chemoprevention, a Realistic Strategy to Reduce the Risk of Cancer \\ $\nabla$}

Cancer chemoprevention has attracted much attention as one of the most practical and realistic strategies in reducing the global burden of cancer [1]. The field of cancer chemoprevention research became prominent and focused at the beginning in the late $1960 \mathrm{~s}$ when Dr. Lee Wattenberg conceptualized this strategy and suggested a mechanistic framework [2], [3], [4]. A broad spectrum of substances has been reported to retain chemopreventive potential, and it is noticeable that many of them were discovered lize Nrf2, thereby facilitating nuclear accumulation of Nrf2. After translocation into nucleus, Nrf2 forms a heterodimer with other transcription factors, such as small Maf, which in turn binds to the 5'-upstream cis-acting regulatory sequence, termed antioxidant response elements (ARE) or electrophile response elements (EpRE), located in the promoter region of genes encoding various antioxidant and phase 2 detoxifying enzymes. Certain dietary chemopreventive agents target Keap 1 by oxidizing or chemically modifying one or more of its specific cysteine thiols, thereby stabilizing Nrf2. In addition, phosphorylation of specific serine or threonine residues present in Nrf2 by upstream kinases may also facilitate the nuclear localization of Nrf2. Multiple mechanisms of Nrf2 activation by signals mediated by one or more of the upstream kinases, such as mitogen-activated protein kinases, phosphatidylionositol-3-kinase/Akt, protein kinase C, and casein kinase- 2 have recently been proposed. This review highlights the cytoprotective gene expression induced by some representative dietary chemopreventive phytochemicals with the Nrf2-Keap1 system as a prime molecular target.

in the plant kingdom. Numerous phytochemicals derived from fruits, vegetables, grains, spices, and herbs are capable of intervening in multi-stage carcinogenesis via distinct mechanisms [5].

The journey of a population of normal cells towards malignancy apparently involves three distinct stages - initiation, promotion and progression. Tumor initiation, a rapid and irreversible process, begins with the genotoxic damage of cellular DNA upon exposure to endogenous or exogenous carcinogens. The initiation stage of chemically induced tumorigenesis involves the metabolic activation of carcinogens and subsequent 
covalent modification of genomic DNA, leading to activation of oncogenes and/or inactivation of tumor suppressor genes. Tumor promotion is recognized as a reversible process characterized by clonal expansion of initiated cells to form a solid mass of proliferating preneoplastic cells. Progression, the final stage of neoplastic transformation, involves the growth of a tumor with invasive and metastatic potential [6].

The recent progress in molecular biology of cancer has identified key components of the intracellular signaling network, especially protein kinases and transcription factors, which function abnormally during the course of cellular transformation and malignancy. In response to carcinogenic insults, the microenvironment of the intracellular signaling network becomes disrupted, thereby favoring malignant transformation of cells. Therefore, one of the essential approaches currently being adopted in studying the mechanisms of chemopreventive phytochemicals is the assessment of their effects on the specific components of the signal transduction network that often becomes awry - either amplified or repressed - during carcinogenesis.

\section{Potentiation of Cellular Antioxidant Defence by Edible Phytochemicals \\ $\nabla$}

Oxidative stress acts as a predisposing factor to multistage carcinogenesis. Reactive oxygen species (ROS), such as superoxide anion, hydrogen peroxide, hydroxyl radical, etc., are constantly generated in cells as unwanted by-products of aerobic metabolism. Although a low physiological level of ROS is scavenged efficiently by the cellular antioxidant defense system, an imbalance between the generation of ROS and the cellular antioxidant capacity turns into a state of "oxidative stress". Oxidative stress contributes to tumorigenesis by either directly attacking DNA to cause genetic alterations or through epigenetic mechanisms that can be achieved by modulating cellular signal transduction pathways [7]. Certain environmental insults (e.g., microbial infection, ultraviolet radiation, and chemical toxicants) act as tumor initiators and/or promoters by inducing steady-state increases in the generation of ROS [7].

In response to oxidative stress, cells attempt to fortify the antioxidant arsenal as the first line of defense. The antioxidant enzymes are involved in not only deactivation of ROS, but also elimination or detoxification of electrophiles [8], [9]. Because of such dual roles, antioxidant enzymes are not unequivocally distinguishable from phase-2 detoxification enzymes, and vice versa [10]. Although antioxidant or detoxifying enzymes are rapidly induced in response to oxidative or electrophilic stress, such adaptive survival response is normally transient and prone to be overwhelmed by excess amoune of ROS or electrophiles. In this context, we may need to fortify or adequately maintain the cellular cytoprotective mechanism through dietary as well as pharmaceutical manipulations. A wide variety of dietary polyphenols and other classes of phytochemicals have been reported to induce the expression of enzymes involved in both cellular antioxidant defenses and elimination/inactivation of electrophilic carcinogens [10]. Induction of such cytoprotective enzymes by edible phytochemicals is recognized as one of the highly effective strategies for preventing cancer in the human population [11].

\section{Nrf2 as a Key Player in Intracellular Signal Transduction Leading to Cytoprotective Enzyme Induction \\ $\nabla$}

Nuclear factor-erythroid-2-related factor 2 (Nrf2), a member of the NF-E2 family of the basic leucine zipper transcription factors, is essential for the coordinated induction of those genes encoding many stress-responsive or cytoptotective enzymes and related proteins, such as $\mathrm{NAD}(\mathrm{P}) \mathrm{H}$ :quinone oxidoreductase-1 (NQO1), superoxide dismutase (SOD), glutathione S-transferase (GST), glutathione peroxidase (GPX), heme oxygenase-1 (HO-1), glutamate cysteine ligase (GCL), catalase, and thioredoxin [8], [9], [10], [11], [12].

The Nrf2-deficient mice failed to induce genes responsible for carcinogen detoxification and protection against oxidative stress [3], [14], [15]. Thus, there was a significantly higher burden of benzo[a]pyrene (B[a]P)-induced gastric neoplasia in Nrf2-deficient mice, which were less responsive to the chemopreventive agent oltipraz [16]. A naturally occurring chemopreventive agent, sulforaphane, reduced $\mathrm{B}[\mathrm{a}] \mathrm{P}$-induced forestomach tumorigenesis in ICR mice, most likely via the induction of phase 2 detoxification/antioxidant enzymes, as this protective effect was abrogated in Nrf2-null mice [17]. Besides its role in regulating carcinogen detoxification and cellular antioxidative defense, Nrf2 also has anti-inflammatory functions [18], [19] and thus represents a novel therapeutic approach for the treatment or prevention of inflammatory disorders [20]. In a recent study, Khor et al. reported that the aggravation of dextran sulfate sodium-induced colitis in $\mathrm{Nrf2}^{-1-}$ mice was associated with decreased expression of HO-1, NQO-1, UDP-glucuronyltransferase 1A1 (UGT1A1), and GST $\mu-1$ [21]. In addition, levels of pro-inflammatory mediators, such as cyclooxygenase-2, inducible nitric oxide synthase, interleukin (IL)- $1 \beta$, IL- 6 , and tumor necrosis factor alpha (TNF- $\alpha$ ), were significantly elevated in the colonic tissues of $\mathrm{Nrf2}^{-/}$mice as compared to their wild-type counterparts [21]. Therefore, targeted activation of the Nrf2 signaling accounts for the chemopreventive effects elicited by some dietary phytochemicals capable of suppressing oxidative and/or inflammatory stress.

In resting cells, $\mathrm{Nrf2}$ resides in the cytoplasm by forming an inactive complex with the repressor Kelch-like ECH-associated protein 1 (Keap1), which is anchored to the actin cytoskeleton. This tight interaction presents $\mathrm{Nrf} 2$ for ubiquinination followed by proteasomal degradation. Keap 1 associates with Cullin 3 (Cul3) and Rbx1 to form a functional E3 ubiquitin ligase complex that targets multiple lysine residues located in the N-terminal Neh2 domain of Nrf2 for ubiquitination. So, Keap1 functions as a substrate adaptor protein for a Cul3-dependent E3 ubiquitin ligase complex and thereby regulates steady-state levels of Nrf2 [22], [23]. Under oxidative or electrophilic stress, Nrf2 is stabilized and translocated to the nucleus, where it transactivates ARE-regulated genes [9], [11]. Widely accepted mechanisms underlying nuclear translocation of Nrf2 and subsequent transactivation of ARE-regulated genes include (a) stabilization of cytoplasmic Nrf2 through blockade of its ubiquitination and proteasomal degradation by Keap1-Cul3 complex [24], and (b) dissociation of Nrf2 from Keap1 via phosphorylation of serine [25] or threonine [26] residues of Nrf2 ( $\bullet$ Fig. 1). After migration to the nucleus, Nrf2 undergoes heterodimeric combinations with other transcription factors, such as small Maf protein and binds to the 5 -upstream cis-acting regulatory sequence, termed antioxidant response elements (ARE) or electrophile response elements 


\section{Nrf2 stabilization}

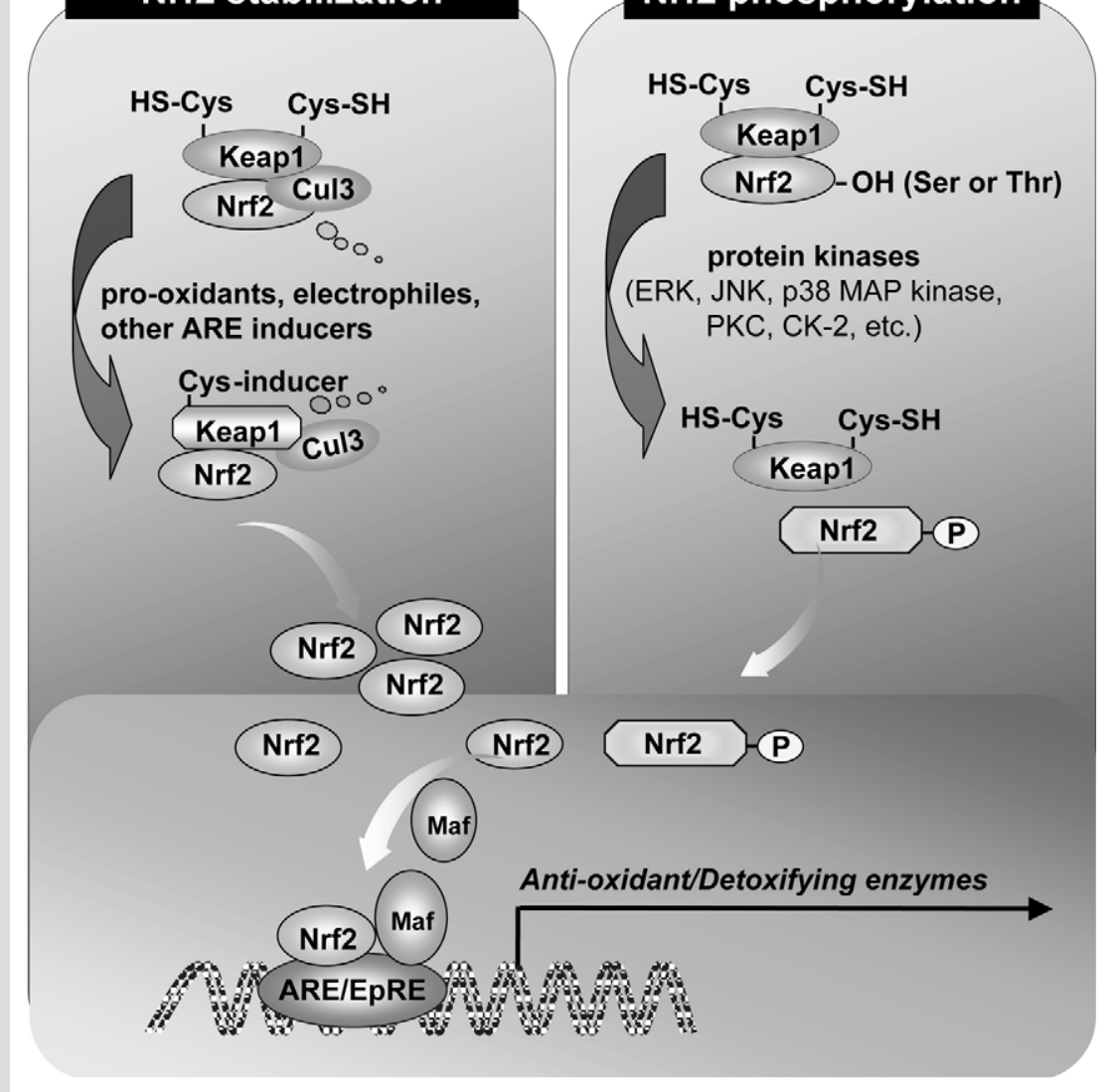

Fig. 1 Proposed mechanisms for Nrf2-ARE-mediated signaling. Nrf2 can be activated by at least two mechanisms that include: (i) stabilization of Nrf2 via Keap1 cysteine thiol modification and (ii) phosphorylation of Nrf2 by upstream kinases. Under physiological conditions, Nrf2 is sequestered in the cytoplasm as an inactive complex with Keap1. (left) Keap1 is a substrate adaptor protein for Cul3dependent ubiquitin ligase complex. Under basal conditions, Keap1 targets Nrf2 for ubiquitin-dependent degradation and represses $\mathrm{Nrf2-depend-}$ ent gene expression. Some ARE inducers (e.g., prooxidants, electrophiles and phase- 2 enzyme inducing chemopreventives) can modify critical cysteine residue(s) (e. g., Cys151) of Keap1, which results in a conformational change in Keap1 and the inability of Cul3 to ubiquitinate Nrf2. Covalently modified or oxidized Keap 1 is then polyubiquitinated by Cul3 and undergoes proteasomal degradation, thereby allowing Nrf2 to get stabilized and accumulated in nucleus. (right) Alternatively, activation of protein kinases, such as PKC, JNK, ERK and CK2 induces Nrf2 phosphorylation, which may stimulate the dissociation of Nrf2 from its repressor Keap1 and subsequent translocation into nucleus. Phosphorylation of $\mathrm{Nrf2}$ is also considered to facilitate its interaction with the transcriptional coactivator $\mathrm{CBP}$ / p300 and recruitment of components of transcription initiation machinery.
(EpRE), located in the promoter region of genes encoding various antioxidant/detoxifying enzymes [29].

Certain dietary chemopreventive agents target Keap1 by oxidizing or chemically modifying its specific cysteine thiols [5], [9], [10], [11], [30], [31], [32]. The oxidation of Keap1 cysteine thiols can be mediated by some edible polyphenols. In this context, it is noticeable that among flavonoids, the higher their intrinsic potential to generate oxidative stress and redox cycling, the stronger their potency as inducers of ARE-mediated gene expression [33]. Polyphenols can undergo oxidation either enzymatically or spontaneously to form quinoids, which can be reduced back to parental molecules, and during such redox process ROS can be generated. For instance, the green tea polyphenol (-)-epigallocatechin gallate (EGCG) was found to produce substantial amount of $\mathrm{H}_{2} \mathrm{O}_{2}$ under cell culture conditions [34], [35]. Therefore, it is paradoxical that the activation of Nrf2-ARE signaling by antioxidant polyphenols to induce cytoprotective enzymes is attributable, at least in part, to their prooxidant activity.

Keap1 is a cysteine-rich homodimeric, multi-domain zinc metalloprotein [36]. Some inducers of cytoprotective enzymes or their reactive metabolites/intermediates can directly interact with critical sensor cysteine residues of Keap1, which has been proposed to diminish the affinity of Nrf2 for Keap1, stimulating their dissociation. Many polyphenols undergo oxidation to produce reactive quinone derivatives that are electrophilic Michael reaction acceptors. It has been suggested that some quinone derivatives of polyphenol inducers can oxidize two highly reactive cysteine thiol groups of Keap1, resulting in disulfide bond formation [37]. This possibility was corroborated by the linear correlation between the antioxidant enzyme-inducing potencies of di- phenols and the extent of their redox potential in terms of ability to release electrons [37]. Other types of phytochemicals with Michael acceptor functionalities directly modify a critical cysteine thiol of Keap1 without undergoing redox cycling. Of particular examples are sulforaphane and structurally related isothiocyanates [38].

The dissociation of Nrf2 from Keap1 as a consequence of Keap1 cysteine thiol modification by ARE inducers used to be considered as a plausible mechanism underlying Nrf2 activation by electrophiles and prooxidants, but this supposition has recently been challenged by some investigators [24]. According to the new paradigm, the direct interaction of the highly reactive cysteine residues of Keap 1 with phase 2 enzyme inducers as well as electrophiles causes conformational changes of this repressor protein, which abrogate the capability of Keap1 to aid proteasomal degradation of Nrf2. Thus, modification of the cysteine 151 residue of human Keap1 by sulforaphane failed to directly release Nrf2 from Keap1, but rather induced conformational changes of Keap1 followed by its proteasomal degradation through polyubiquitination, thereby stabilizing Nrf2 [24]. Besides the C151 residue, other cysteine residues of Keap1 (e.g., C273 and C288) have also been reported to be essential for the Keap1-dependent repression of Nrf2 [39]. Detailed mechanisms underlying the regulation of Nrf2 by Keap1-Cul3 complex in intact cells as well as in those under stress have been reviewed elsewhere [11], [40], [41] and are beyond the scope of this article. In addition to activation of Nrf2 through oxidation or chemical modification of Keap1 cysteine thiols, phosphorylation of specific serine [27] or threonine [26] residues of Nrf2 may facilitate the release of Nrf2 from the Keap1 repression and its subsequent nu- 
clear translocation and interaction with the co-activator CBP/ p300 ( Fig. 1). Alternatively, phosphorylation of the tyrosine 141 residue located in the bric-a-brac, tramtrack, broad complex (BTB) domain makes Keap1 stable, while dephosphorylation at this residue promotes rapid degradation of Keap1 and hence stabilization of Nrf2 [42]. Another novel mechanism of Nrf2 stabilization has recently been proposed by Clements et al. [43]. According to this study, DJ-1/PARK7 (a cancer and Parkinson's disease-associated protein) inhibits Nrf2-Keap1 binding and is indispensable for Nrf2 stabilization and subsequent NQO1 induction [43]. Activation of several upstream kinases, such as mitogen-activated protein (MAP) kinases [25], phosphatidylionositol 3-kinase (PI3K)/Akt [44], protein kinase C (PKC) [27], [45] and casein kinase-2 (CK-2) [46] have been considered to facilitate nuclear translocation and transcriptional activation of Nrf2. On the other hand, glycogen synthase kinase-3 $\beta$ (GSK3 $\beta$ ) negatively regulates Nrf2 signaling via phosphorylation of $\mathrm{Nrf} 2$ at tyrosine [47] or serine [48] residues. Several ARE inducers have been shown to phosphorylate Akt and enhance nuclear translocation of Nrf2 [49], [50], [51], [52], [53], which may result from the inactivation of GSK3 $\beta$ by activated Akt. Nrf2 activation by dietary chemopreventives through modulation of one or more of the upstream kinases have recently been reviewed [8], [9], [12], [54]. - Table 1 lists several representative dietary phytochemicals (structures shown in $\bullet$ Fig. 2) that have the ability to activate Nrf2-ARE signaling. Additional information on chemopreventive phytochemicals targeting the Nrf2-Keap1 system is available in several reviews [5], [7], [8], [9], [10], [11] as well as in the following section.

\section{Chemopreventive Phytochemicals with Nrf2-ARE Activating Ability \\ $\nabla$}

\section{Sulforaphane}

Sulforaphane [1-isothiocyanato-(4R,S)-(methylsulfinyl)butane], a representative isothiocyanate present in broccoli and other cruciferous vegetables, exerts its cancer chemopreventive and cytoprotective effects mainly by the induction of genes encoding phase 2 detoxifying and antioxidant enzymes [55]. The gastrointestinal GPX is a selenoprotein that was suggested to act as a barrier against hydroperoxide absorption but has also been implicated in the control of inflammation and malignant growth [56]. The anticarcinogenic role of GI-GPX is evident from enhanced gastrointestinal tumor formation in gpx2/gpx1 double knockout mice [57]. The GI-GPx promoter harbours an ARE binding site that was activated by sulforaphane or tert-butylhydroquinone (tBHQ) as well as through overexpression of Nrf2 in human hepatoma (HepG2) or human colon cancer (Caco-2) cells [56]. Thus, the antioxidant and anti-inflammatory as well as chemopreventive effects of sulforaphane may be attributable to upregulation of GI-GPx as well as induction of conventional phase 2 detoxifying enzymes.

Sulforaphane, by activating Nrf2 signaling, abrogated toxicity as well as the accumulation of arsenite in cultured murine hepatocytes [58]. Using a human bladder urothelial cell line stably transfected with Nrf2-siRNA, Wang and colleagues [59] demonstrated that compromised Nrf2 expression sensitized the cells to As(III)-induced toxicity. On the other hand, the activation of the Nrf2 pathway by sulforaphane or the known Nrf2-inducer tBHQ rendered these cells more resistant to As(III). Sulforaphane upregulated the expression of detoxifying enzymes including NQO1,
GST and GCL in the small intestine of nrf2-wild-type mice, while the nrf2-null mice displayed lower levels of these enzymes [60]. Livers obtained from the $n r f 2$ wild-type and the $n r f 2$ knockout mice after treatment with vehicle or sulforaphane for 3 and $12 \mathrm{~h}$ exhibited differential gene expression profiles determined by the Affymetrix $39 \mathrm{~K}$ oligonucleotide microarray [61]. In this study, the Nrf2-dependent, sulforaphane-inducible genes were identified. These include phase $1 / 2$ xenobiotic metabolizing enzymes and phase 3 transporters. Unexpected clusters of genes include those for heat shock proteins, ubiquitin/26S proteasome subunits, and lipid metabolism. Topical application of sulforaphane ( $100 \mathrm{nmol}$ ) for 14 consecutive days inhibited skin carcinogenesis induced by 7,12-dimethylbenz [a]anthracene plus 12-Otetradecanoylphorbol 13-acetate in $\mathrm{C} 57 \mathrm{BL} / 6$ mice, whilst no such chemopreventive effects were elicited in the $n r f 2$-deficient mice [62].

Sulforaphane induces Nrf2-driven phase 2 enzyme expression by modulating the activation of MAP kinases [54], [63], [64], [65], [66], [67]. Sulforaphane and its sulfide analogue, erucin elevated the mRNA expression of NQ01, UGT1A1, and multidrug transporter protein (MRP) 2 in Caco-2 cells by activating PI3K/ Akt- or MAP kinase kinase (MEK)/extracellular signal-regulated protein kinase (ERK)-mediated signaling [65]. Involvement of ERK1/2 and JNK in sulforaphane-induced ARE-transcription activities was also observed in murine keratinocytes [66]. Unlike ERK and JNK, p38 MAP kinase appeared to negatively regulate Nrf2 activation [67]. The p38 MAP kinase phosphorylated purified Nrf2 protein at a site presumably different from those phosphorylated by other kinases [67]. Overexpression of p38 MAP kinase isoforms caused an increase in the interaction between Nrf2 and Keap1 and attenuated constitutive and inducible Nrf2 translocation into nucleus [67]. However, the role of p38 MAP kinase in Nrf2 activation is still controversial. Sulforaphane induced HO-1 expression in HepG2 cells by downregulating p38 MAP kinase, thereby activating the Nrf2-ARE signaling [67]. The $26 \mathrm{~S}$ proteasome is responsible for degradation of abnormal proteins and may play a role in cell survival upon oxidative stress. Sulforaphane enhanced the expression of the catalytic subunits of the proteasome as well as proteasomal peptidase activities in murine neuroblastoma Neuro2A cells [68]. Sulforaphane treatment protected these cells from hydrogen peroxide-mediated cytotoxicity in a manner dependent on proteasomal function. In addition to the modulation of upstream kinases, the mechanism of Nrf2 activation by sulforaphane involves a direct modification of cysteine residue(s) on Keap1, facilitating dissociation of Nrf2 from Keap1 [38]. As sulforaphane is an electrophile, it can react with protein thiols to form thionoacyl adducts. Although sulforaphane activates Nrf2-ARE signaling through specific modifications of the Keap1 protein, this isothiocyanate displays a distinctly different pattern of Keap 1 modification compared with conventional ARE inducers that modify Keap1 by alkylation. Thus, sulforaphane modifies Keap1 predominantly in the Kelch domain, rather than in the central linker domain, which is targeted by previously characterized ARE inducers [38]. Moreover, sulforaphane treatment in vivo did not lead to the accumulation of ubiquitinated Keap1, which was consisitent with the previous finding that sulforaphane inhibits Keap1-dependent ubiquinitation of Nrf2 without inducing Keap1 ubiquitination [23]. A single cysteine-to-serine substitution (C151S) at reside 151 within the BTB domain of Keap1 confered significant resistance to inhibition by sulforaphane [22]. Treatment of cells with sulforaphane decreased the level of Cul3 that was co-purified 
Table 1 Cellular antioxidant defence through activation of the Nrf2 signaling by chemopreventive phytochemicals

\begin{tabular}{|c|c|c|c|}
\hline Compound (Dose) & Molecular mechanisms & Experimental systems & Ref. \\
\hline \multicolumn{4}{|l|}{ Sulforaphane } \\
\hline$(2-200 \mu \mathrm{M})$ & $\begin{array}{l}\uparrow \text { Stabilization and nuclear accumulation of Nrf2 via } \\
\text { cysteine thioacetylation of Keap- } 1\end{array}$ & $\begin{array}{l}\text { Human Keap-1-transfected HEK293 cells } \\
\text { and in vitro study }\end{array}$ & [38] \\
\hline$(20 \mu \mathrm{M})$ & $\begin{array}{l}\downarrow \text { Phosphorylation of p38 MAP kinase, } \uparrow \text { Nrf2-ARE activity, } \\
\uparrow \text { HO- } 1 \text { expression }\end{array}$ & HepG2 cells & [67] \\
\hline $\begin{array}{l}(9 \mu \mathrm{mol} / \text { mouse per day for } 7 \\
\text { days) }\end{array}$ & $\begin{array}{l}\uparrow \text { mRNA expression of NQO1, GCL, GST and glutathione } \\
\text { reductase, } \uparrow \text { activities of NQO1, GST, glucose- } 6 \text {-phosphate } \\
\text { dehydrogenase, UDP-glucose dehydrogenase, maleic } \\
\text { enzyme, and carboxylesterase }\end{array}$ & nrf2 -wild type mice & {$[60]$} \\
\hline ( $3 \mu \mathrm{mol} / \mathrm{g}$ for 14 days) & $\begin{array}{l}\uparrow \text { Expression and activities of NQO1 and GST, } \uparrow \text { expression } \\
\text { of GCS }\end{array}$ & nrf2 -wild type mice & [119] \\
\hline \multicolumn{4}{|c|}{ 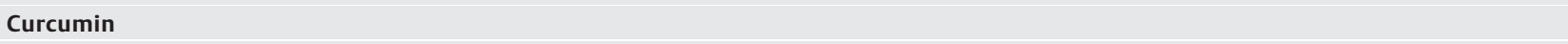 } \\
\hline ( $0.05 \%$ in diet) & $\begin{array}{l}\uparrow \text { Activity, mRNA and protein expression of GST and NQO1 in } \\
\text { liver and lungs, } \uparrow \text { expression, nuclear translocation and ARE } \\
\text { binding of Nrf } 2 \text { in liver and lungs, } \uparrow \mathrm{B}[\mathrm{a}] \mathrm{P} \text { detoxification }\end{array}$ & $\begin{array}{l}\text { Inbred Swiss albino mice treated with } \\
\mathrm{B}[\mathrm{a}] \mathrm{P}\end{array}$ & [73] \\
\hline$(20 \mu \mathrm{M})$ & $\begin{array}{l}\uparrow \text { GSTP-1 mRNA expression, } \uparrow \text { Nrf2-ARE-regulated GSTP-1 } \\
\text { reporter gene activity }\end{array}$ & HepG2 cells & [76] \\
\hline$(15 \mu \mathrm{M})$ & $\begin{array}{l}\uparrow \text { ARE-mediated expression of HO- } 1 \text { and GCLM, } \uparrow \text { PKC } \delta \text {, } \\
\uparrow \text { p38 MAP kinase, } \uparrow \text { Nrf2 }\end{array}$ & Human monocytes & [77] \\
\hline$(10-30 \mu \mathrm{M})$ & $\begin{array}{l}\uparrow \text { Phosphorylation of } \mathrm{p} 38 \text { MAP kinase, } \uparrow \text { dissociation of } \\
\text { Nrf2-Keap } 1, \uparrow \text { Nrf2 binding to ho-1-ARE, and } \uparrow \text { expression } \\
\text { and activity of HO-1 }\end{array}$ & NRK- $52 \mathrm{E}$ cells and LLC-PK cells & [74] \\
\hline$(10-15 \mu \mathrm{M})$ & $\begin{array}{l}\uparrow \text { Nuclear translocation and DNA binding of Nrf2-ARE, } \\
\uparrow \mathrm{GCLC} \text { and GCLM mRNA and protein expression, } \uparrow \mathrm{GSH}\end{array}$ & HBE1 cells & [75] \\
\hline$(10 \mu \mathrm{M})$ & $\begin{array}{l}\uparrow \text { Activation of PKC and p38 MAP kinase, } \uparrow \text { Nrf2 activation, } \\
\text { and } \uparrow \text { expression of } \mathrm{HO}-1\end{array}$ & HepG2 cells & [78] \\
\hline$(20 \mu \mathrm{M})$ & $\begin{array}{l}\uparrow \mathrm{HO}-1 \text { expression, } \uparrow \mathrm{Nrf} 2 \text { nuclear translocation, } \\
\uparrow \text { ARE luciferase activity }\end{array}$ & rat vascular smooth muscle cells & [80] \\
\hline$(200 \mathrm{mg} / \mathrm{kg})$ & $\begin{array}{l}\uparrow \text { DNA binding of Nrf2-ARE in liver, } \uparrow \text { HO- } 1 \text { expression } \\
\text { and activity in liver, } \downarrow \text { dimethylnitrosoamine-induced } \\
\text { hepatotoxicity }\end{array}$ & $\begin{array}{l}\text { Curcumin given by gavage to male } \\
\text { Albino rats }\end{array}$ & [79] \\
\hline \multicolumn{4}{|c|}{ 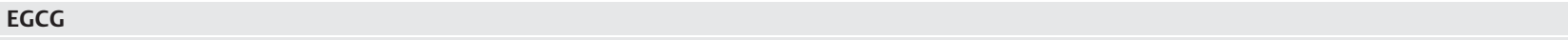 } \\
\hline$(25 \mu \mathrm{M})$ & $\uparrow$ MAP kinases, $\uparrow$ ARE luciferase activity & HepG2 cells & [85] \\
\hline$(20 \mu \mathrm{M})$ & $\begin{array}{l}\uparrow \text { HO- } 1 \text { expression, } \uparrow \text { Nrf2 nuclear translocation, } \uparrow \text { Akt, } \\
\uparrow p 38 \text { MAP kinase }\end{array}$ & B lymphoblasts & [49] \\
\hline$(50 \mu \mathrm{M})$ & $\begin{array}{l}\uparrow \mathrm{HO}-1 \text { expression, } \uparrow \mathrm{Nrf} 2 \text { nuclear level, } \uparrow \text { ARE luciferase } \\
\text { activity, } \uparrow \text { ERK, } \uparrow \text { Akt }\end{array}$ & Bovine aortic endothelial cells & {$[50]$} \\
\hline$(100 \mu \mathrm{M})$ & $\begin{array}{l}\uparrow \text { Nuclear localization of Nrf2, } \uparrow \text { Nrf2-ARE DNA binding, } \\
\uparrow A k t, \uparrow E R K, \uparrow \text { mRNA and protein expression of GCL, } \\
\text { HO- } 1 \text { and MnSOD }\end{array}$ & MCF-10A cells & [51] \\
\hline (20 mg/kg; gavage) & $\begin{array}{l}\downarrow \text { Growth of implanted colon tumor in nude mice, } \\
\uparrow \text { protein expression of Nrf2, and mRNA expression of } \\
\text { UGT1A, UGT1A8, UGT1A10 and Nrf2 in implanted colon } \\
\text { tumors }\end{array}$ & $\begin{array}{l}\text { Colon tumors orthotopically implanted } \\
\text { in cecum of nude mice }\end{array}$ & [86] \\
\hline 10 or $20 \mathrm{mg} / \mathrm{kg}$ & $\begin{array}{l}\uparrow \text { Expression of UGT1A10 and Nrf2 protein and mRNA, } \\
\downarrow \text { formation of aberrant crypt foci }\end{array}$ & $\begin{array}{l}\text { Balb/c nude mice treated with or } \\
\text { without 2-amino-3-methylimidazo[4,5- } f] \\
\text { quinoline }\end{array}$ & [121] \\
\hline \multicolumn{4}{|l|}{ Diallyl sulfide } \\
\hline$(1 \mathrm{mM})$ & $\begin{array}{l}\uparrow \mathrm{HO}-1 \text { mRNA and protein expression, } \uparrow \text { Nrf2 nuclear } \\
\text { translocation, } \uparrow \text { Nrf2 DNA binding activity, } \uparrow \text { ERK and } p 38, \\
\text { protected cells from hydrogen peroxide-induced toxicity }\end{array}$ & HepG2 cells & [89] \\
\hline \multicolumn{4}{|l|}{ Diallyl trisulfide } \\
\hline$(100 \mu \mathrm{M})$ & $\begin{array}{l}\uparrow \mathrm{HO}-1 \text { and NQO-1 gene expression, } \uparrow \mathrm{Nrf} 2 \text { protein level } \\
\text { and ARE activity via activation of calcium-dependent } \\
\text { signaling }\end{array}$ & HepG2 cells & [90] \\
\hline \multicolumn{4}{|l|}{ S-Allylcysteine } \\
\hline $100 \mathrm{mg} / \mathrm{kg}$ & $\begin{array}{l}\uparrow \text { Activities of SOD, catalase, GPx, GST and NQO1, } \\
\uparrow \text { nuclear translocation of Nrf2, } \downarrow \text { chromium-induced } \\
\text { cell death }\end{array}$ & $\mathrm{K}_{2} \mathrm{Cr}_{2} \mathrm{O}_{7}$-treated rat liver & [120] \\
\hline \multicolumn{4}{|l|}{ Resveratrol } \\
\hline$(15 \mu \mathrm{M})$ & $\uparrow$ Expression and activity of $\mathrm{HO}-1$ via activation of $\mathrm{Nrf} 2$ & PC12 cells & [99] \\
\hline$(10 \mu \mathrm{M})$ & $\begin{array}{l}\uparrow \text { GCL activity, } \uparrow \text { GSH synthesis, } \downarrow \text { CSE-induced } \\
\text { posttranscriptional (aldehyde/carbonyl adduct or } \\
\text { nitration) modification of Nrf2 and Keap } 1, \uparrow \text { Nrf2 nuclear } \\
\text { translocation }\end{array}$ & $\begin{array}{l}\text { Human small airway epithelial cells and } \\
\text { A549 cells }\end{array}$ & [100] \\
\hline
\end{tabular}




\begin{tabular}{|c|c|c|c|}
\hline Compound (Dose) & Molecular mechanisms & Experimental systems & Ref. \\
\hline$(25-50 \mu \mathrm{M})$ & $\begin{array}{l}\uparrow \text { Expression of NQO1 protein and mRNA, } \uparrow \text { NQO-1 } \\
\text { activity, } \uparrow \text { nqo-1-ARE activity, } \uparrow \text { phosphorylation and } \\
\text { nuclear translocation of Nrf2 }\end{array}$ & K562 cells & [97] \\
\hline \multicolumn{4}{|l|}{ Lycopene } \\
\hline$(2-4 \mu \mathrm{M})$ & $\begin{array}{l}\uparrow \text { GCS-ARE and NQO1-ARE activity, } \uparrow \text { mRNA and/or } \\
\text { protein expression of GCS and NQO-1, } \uparrow \text { glutathione, } \\
\downarrow \text { ROS }\end{array}$ & MCF-7 and HepG2 cells & [105] \\
\hline \multicolumn{4}{|l|}{ Capsaicin } \\
\hline$(200 \mu \mathrm{M})$ & $\begin{array}{l}\uparrow \text { ROS, PI3K/Akt expression, } \uparrow \mathrm{HO}-1 \text { protein and mRNA } \\
\text { expression, } \downarrow \text { HO- } 1 \text { activity, } \downarrow \text { NQO } 1 \text { expression and } \\
\text { activity, } \uparrow \text { activation of Nrf2 }\end{array}$ & HepG2 cells & [52] \\
\hline \multicolumn{4}{|c|}{ 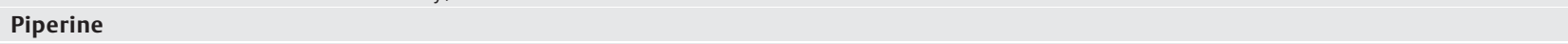 } \\
\hline$(50 \mu \mathrm{M})$ & $\begin{array}{l}\uparrow \text { Phosphorylation of MAP kinases, } \uparrow \text { JNK-mediated HO- } 1 \\
\text { expression, } \uparrow \text { Nrf2 nuclear translocation }\end{array}$ & $\begin{array}{l}\text { Mouse auditory House Ear Institute } \\
\text { organ of Corti-1 (HEI-OC1) cells }\end{array}$ & [122] \\
\hline \multicolumn{4}{|l|}{ Carnosol } \\
\hline$(10 \mu \mathrm{M})$ & $\begin{array}{l}\uparrow \text { HO- } 1 \text { mRNA and protein expression, } \uparrow \text { binding of Nrf2 } \\
\text { to ho-1-ARE, } \uparrow \text { activation of ERK, p } 38 \text { MAP kinase and JNK }\end{array}$ & PC12 cells & [110] \\
\hline \multicolumn{4}{|l|}{ Cinnamaldehyde } \\
\hline$(100 \mu \mathrm{M})$ & $\begin{array}{l}\uparrow \text { Expression of } \mathrm{HO}-1, \uparrow \text { nuclear translocation of } \mathrm{Nrf} 2 \text {, } \\
\uparrow \text { ho-1-ARE reporter activity }\end{array}$ & Human endothelial cells & [111] \\
\hline \multicolumn{4}{|c|}{ 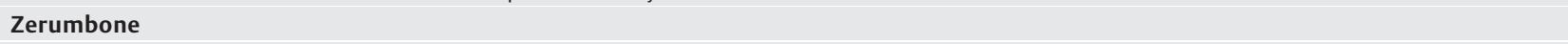 } \\
\hline$(1-25 \mu \mathrm{M})$ & $\begin{array}{l}\uparrow \text { Expression of GSTP-1, GCL, GPx and HO-1, } \uparrow \text { nuclear } \\
\text { translocation of Nrf2 }\end{array}$ & RL34 cells & [113] \\
\hline \multicolumn{4}{|c|}{ 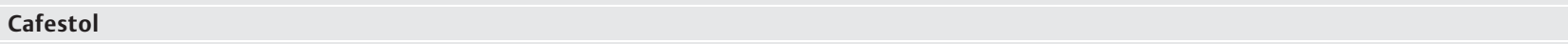 } \\
\hline (0.025\% diet) & $\begin{array}{l}\uparrow \text { Expression and activities of NQO- } 1 \text { and GST in cytosolic } \\
\text { fraction of small intestinal tissue }\end{array}$ & nrf2 wild type mice & [119] \\
\hline \multicolumn{4}{|l|}{ Kahweol } \\
\hline & $\begin{array}{l}\uparrow \text { Expression of HO- } 1 \text { mRNA and protein, } \uparrow \mathrm{HO}-1 \text { activity, } \\
\uparrow \text { phosphorylation of Akt and p38 MAP kinase, } \uparrow \text { nuclear } \\
\text { translocation of Nrf2 }\end{array}$ & SH-SY5Y cells & [123] \\
\hline \multicolumn{4}{|l|}{ Chalcone } \\
\hline$(25 \mu \mathrm{M})$ & $\begin{array}{l}\uparrow \text { HO- } 1 \text { expression, } \uparrow \text { nuclear } \mathrm{Nrf2} \text { level, } \uparrow \text { ARE luciferase } \\
\text { activity, } \uparrow \text { thioredoxin reductase promoter activity }\end{array}$ & Endothelial cells & [114] \\
\hline \multicolumn{4}{|l|}{ Xanthohumol } \\
\hline$(4 \mu \mathrm{M})$ & $\begin{array}{l}\uparrow \mathrm{NQO} 1 \text { expression, } \uparrow \text { activation of } \mathrm{Nrf} 2 \text { via covalent } \\
\text { modification of Keap-1 at cysteine } 27 \text { residue }\end{array}$ & Murine Hepa1c1c7 cells & [118] \\
\hline \multicolumn{4}{|c|}{ 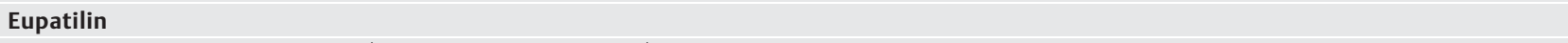 } \\
\hline$(150 \mu \mathrm{M})$ & $\begin{array}{l}\uparrow \text { Phosphorylation of ERK, } \uparrow \text { nuclear translocation of Nrf2, } \\
\uparrow \text { HO- } 1 \text { expression }\end{array}$ & Feline ileal smooth muscle cells & [124] \\
\hline \multicolumn{4}{|l|}{ Isoorientin } \\
\hline$(5 \mu \mathrm{g} / \mathrm{mL})$ & $\begin{array}{l}\uparrow \text { Phosphorylation of PI3K/Akt, } \uparrow \text { nuclear accumulation } \\
\text { of Nrf2, } \uparrow \text { expression of HO-1, NQO- } 1 \text { and peroxiredoxin }\end{array}$ & HepG2 cells & [125] \\
\hline \multicolumn{4}{|c|}{ 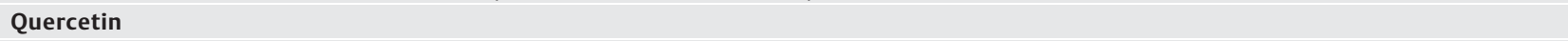 } \\
\hline $50 \mu \mathrm{M}$ & $\begin{array}{l}\uparrow \mathrm{HO}-1 \text { expression, } \uparrow \text { nuclear level of } \mathrm{Nrf} 2, \downarrow \text { ROS } \\
\text { generation, } \downarrow \mathrm{H}_{2} \mathrm{O}_{2} \text { - or } t \text {-butyl hydroperoxide-induced } \\
\text { cell death }\end{array}$ & $\begin{array}{l}\text { Adult human retinal pigment epithelial } \\
\text { cells }\end{array}$ & [126] \\
\hline $10-40 \mu \mathrm{M}$ & $\begin{array}{l}\uparrow \text { NQO-1 mRNA expression, } \uparrow \text { NQO1-ARE DNA binding, } \\
\uparrow \text { nuclear translocation of Nrf2, } \downarrow \text { Nrf2 ubiquitination, } \\
\uparrow n r f 2 \text {-mediated ARE activity }\end{array}$ & HepG2 cells & [127] \\
\hline $100 \mu \mathrm{M}$ & $\begin{array}{l}\uparrow \text { GSH level, } \downarrow \text { lipid peroxidation } \uparrow \text { HO- } 1 \text { activity, } \\
\uparrow \text { nuclear Nrf2 expression }\end{array}$ & $\begin{array}{l}\text { Ethanol-stimulated human hepatocytes } \\
\text { isolated from liver cancer patients }\end{array}$ & [128] \\
\hline $25 \mu \mathrm{M}$ & $\begin{array}{l}\uparrow \text { HO-1-ARE and GI-GPx-ARE activity, } \uparrow \text { GI-GPx } \\
\text { promoter activity, } \uparrow \text { nuclear Nrf2 expression }\end{array}$ & HepG2 cells & [129] \\
\hline \multicolumn{4}{|c|}{$\begin{array}{l}\text { 3-0-Caffeoyl-1-methylquinic } \\
\text { acid }\end{array}$} \\
\hline$(20-200 \mu \mathrm{M})$ & $\begin{array}{l}\uparrow \mathrm{mRNA} \text { expression of HO-1, GCL, GR, and GST, } \uparrow \mathrm{HO}-1 \\
\text { protein expression, } \uparrow \text { phosphorylation of JNK and ERK, } \\
\uparrow \text { nuclear translocation of Nrf2 }\end{array}$ & Human umbilical vein endothelial cells & [130] \\
\hline \multicolumn{4}{|l|}{ Brazilin } \\
\hline$(10 \mathrm{mM})$ & $\begin{array}{l}\uparrow \text { Phosphorylation of Akt and ERK, } \uparrow \text { expression of } \\
\text { HO- } 1 \text { mRNA and protein, } \uparrow \text { nuclear translocation of Nrf2 }\end{array}$ & HEI-OC 1 cells & [131] \\
\hline \multicolumn{4}{|l|}{ Chlorophyllin } \\
\hline$(50 \mu \mathrm{M})$ & $\begin{array}{l}\uparrow \text { Phosphorylation of PI3K/Akt, } \uparrow \text { nuclear accumulation } \\
\text { of Nrf2, } \uparrow \text { expression of HO- } 1 \text { and NQO1 }\end{array}$ & Human umbilical vein endothelial cells & [132] \\
\hline
\end{tabular}




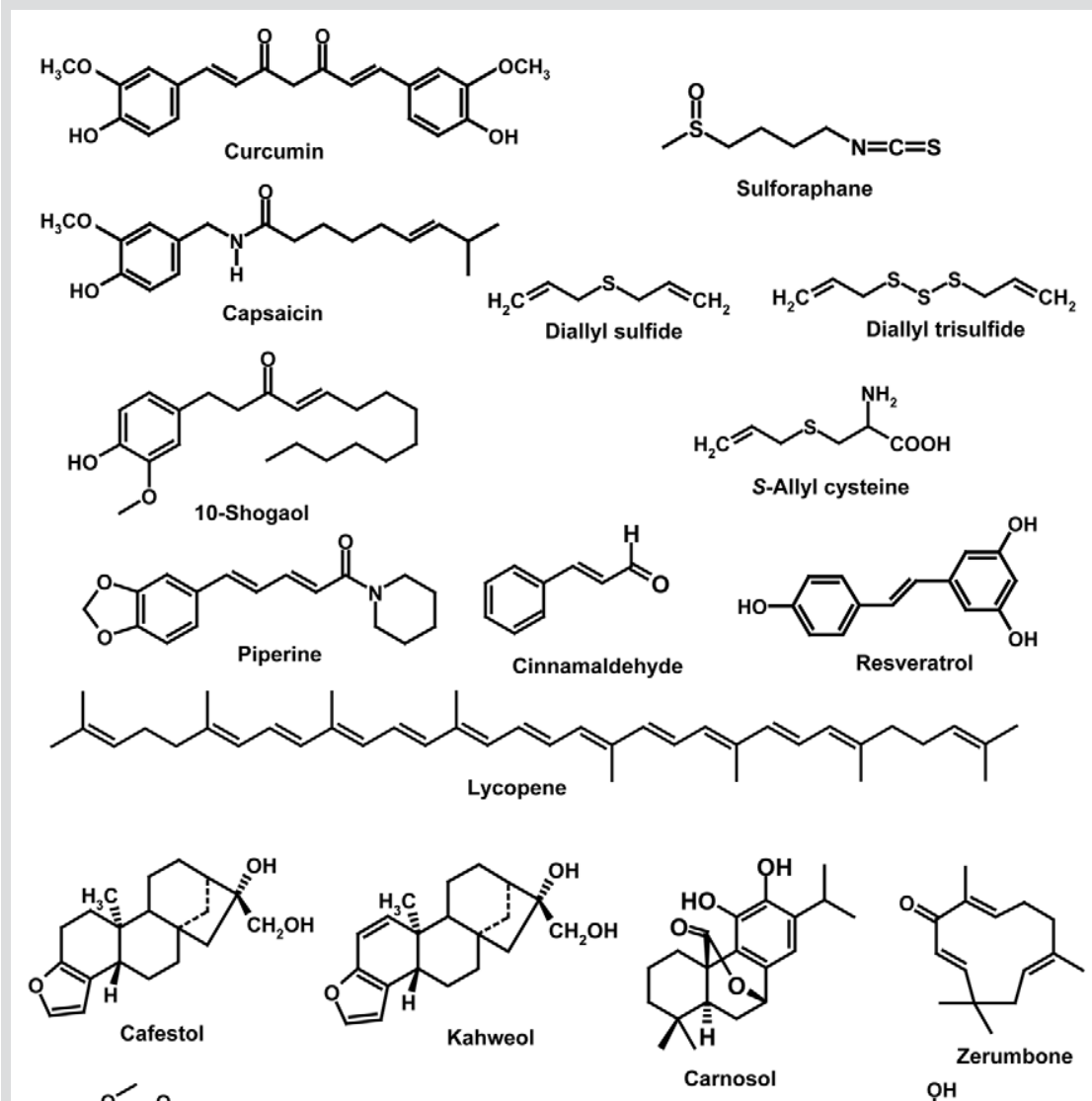

Fig. 2 Selected chemopreventive phytochemicals that can activate Nrf2-ARE signaling.<smiles>Oc1ccc2c(c1)OC[C@@]1(O)Cc3cc(O)c(O)cc3[C@H]21</smiles><smiles>O=c1cc(-c2ccc(O)c(O)c2)oc2cc(O)c(Cl)c(O)c12</smiles>

Isoorientin<smiles>O=C(O[C@H]1Cc2c(O)cc(O)cc2O[C@H]1c1cc(O)c(O)c(O)c1)c1cc(O)c(O)c(O)c1</smiles><smiles>CCOc1ccc(-c2cc(=O)c3c(O)c(OC)c(O)cc3o2)cc1OC</smiles>

Eupatilin<smiles>COC1(C(=O)O)CC(O)C(O)C(OC(=O)/C=C/c2ccc(O)c(O)c2)C1</smiles>

with the wild-type Keap1-CBD protein following affinity purification. Importantly, the amount of Cul3 that was co-purified with the Keap1-C151S protein was greater than the amount of
Cul3 that was co-purified with the wild-type Keap1 protein following treatment with sulforaphane [22]. Although a series of studies reported that sulforaphane activated Nrf2 signaling 
largely by cysteine thiol modification and subsequent dissociation of Nrf2 from Keap1, a recent study by Eggler and colleagues [24] demonstrated that thiol modification of Keap1 cysteine 151 by sulforaphane failed to cause direct dissociation of Nrf2 from Keap1. The study, rather, provided a new insight into the mechanism of Nrf2 activation by sulforaphane. According to this study, the covalent modification of Keap1 cysteine 151 by sulforaphane leads to structural changes of Keap1, which then undergoes polyubiquitination and proteasomal degradation, thereby allowing Nrf2 to escape from Cul3-dependent proteasomal degradation [24]. A sulforaphane analogue, 6-methylsulphinylhexyl isothiocyanate isolated from Japanese wasabi was also found to induce cytoprotective gene expression via the Nrf2-ARE signaling [69]. Likewise, phenethyl isothiocyanate induced HO-1 expression and ARE activity in human prostate cancer (PC3) cells via ERK and JNK-mediated phosphorylation of Nrf2 and subsequent Nrf2 nuclear translocation [25].

\section{Curcuminoids}

Curcumin is a diferuloylmethane derived from the rhizomes of turmeric (Curcuma longa Linn, Zingiberaceae). Its chemopreventive effects have been extensively investigated and well defined [70], [71]. Curcumin targets the Nrf2-ARE signaling pathway to induce phase 2 detoxifying enzymes. Dietary curcumin enhanced not only the Nrf2 levels but also its nuclear translocation and the ARE binding in liver and lung of mice. Wild-type C57BL/ $6 \mathrm{~J}$ and $\mathrm{C} 57 \mathrm{BL} / 6 \mathrm{~J} / \mathrm{nrf2}(-/-)$ mice were given a single oral dose of curcumin $(1,000 \mathrm{mg} / \mathrm{kg})$ and liver and small intestine were collected for DNA microarray analysis. Among those well-defined genes, 822 (664 induced and 158 suppressed) and 222 (154 induced and 68 suppressed) were curcumin-regulated Nrf2-dependent genes identified in the liver and small intestine, respectively [72]. As expected, many phase 2 detoxification/antioxidant enzyme genes were among the identified genes. Induction of carcinogen detoxifying enzymes, such as GST isoforms and NQO1 by dietary curcumin in mice paralleled the curcuminmediated activation of $\mathrm{Nrf} 2$, leading to increased detoxification of benzo[a]pyrene [73].

Balogun et al. [74] reported that curcumin disrupted the Nrf2Keap1 complex, leading to increased Nrf2 binding to ARE and subsequent increases in the expression and the activity of HO-1 in porcine renal epithelial proximal tubule (LLC-PK $)_{1}$ cells and/ or rat kidney epithelial (NRK-52E) cells via activation of p38 MAP kinase. Curcumin also enhanced the expression of GCL at mRNA and protein levels in immortalized human bronchial epithelial (HBE1) cells by promoting nuclear translocation and DNA binding of Nrf2 [75]. The treatment of HepG2 cells with curcumin resulted in the elevation of GSTP-1 mRNA and Nrf2ARE-regulated GSTP1 reporter gene activity [76]. Curcumin activated ARE-mediated expression of HO-1 and GCLM in human monocytes via activation of PKC delta, an enzyme upstream of p38 MAP kinase and Nrf2 [77]. Curcumin induced HO-1 expression by activating Nrf2 via ROS generation, activation of PKC and p38 MAP kinase, and the inhibition of phosphatase activity in human hepatoma (HUH-7) cells [78]. ROS production appeared to be mitochondrial in origin, as curcumin treatment resulted in depolarization of the mitochondrial membrane potential. Both HO-1 induction and Nrf2 activation were ROS-dependent. In another study, curcumin induced HO-1 expression and nuclear translocation of Nrf2 in cultured MDA-MB468 breast cancer cells [49]. The compound also induced nuclear localization of Nrf2 and HO-1 expression effectively in wild-type mouse em- bryonic fibroblasts, but not in those from nrf2-deficient mice [49].

Oral administration of curcumin at $200 \mathrm{mg} / \mathrm{kg}$ body weight for four consecutive days resulted in enhanced nuclear accumulation and the ARE-binding of Nrf2 and HO-1 upregulation in rat liver [79]. The induction of HO-1 by curcumin accounted for its protection against dimethylnitrosamine-induced hepatotoxicity in rats. Structurally, curcumin has two $\alpha, \beta$-unsaturated carbonyl groups and can hence act as a Michael reaction acceptor, causing thiol modification of Keap1, followed by Nrf2 nuclear translocation. Consistent with this notion, tetrahydrocurcumin, which lacks an electrophilic $\alpha, \beta$-unsaturated carbonyl functional moiety, failed to induce Nrf2-ARE binding as well as HO-1 induction when given orally to rats [79]. Pae et al. reported that curcumin inhibited serum- and TNF $\alpha$-induced growth of rat vascular smooth muscle cells (rVSMC) and human aortic smooth muscle cells, respectively by activating Nrf2-ARE-mediated induction of HO- 1 and increasing the expression of p21, while its hydrogenated analogue tetrahydrocurcumin did not elicit such growth inhibitory effects [80]. Moreover, co-treatment of rVSMC cells with curcumin and the HO-1 inhibitor tin protoporphyrin partially abolished curcumin-induced p21 WAF1/CIP1 expression and growth inhibition, suggesting that the antiproliferative effect of curcumin is mediated via upregulation of HO-1 [80]. Interestingly, curcumin accelerated the nuclear translocation of Nrf2 via activation of PI3K and p38 MAP kinase in vascular smooth muscle cells, which was associated with increased expression and the promoter activity of aldose reductase [81]. Demethoxy- and bisdemethoxycurcumin induced HO-1 promoter activity more effectively than did curcumin in a mouse pancreatic $\beta$-cell line [53]. The induction was dependent on the presence of ARE sites containing enhancer regions (E1 and E2) in the HO-1 promoter as well as nuclear translocation of Nrf2. Real-time quantitative RT-PCR analysis showed significant elevation in the mRNA levels of two other phase 2 enzymes, GCLM and NQO1 as well [53]. Treatment of HepG2 cells harbouring GI-GPX-promoter constructs with curcumin resulted in a significant induction of the reporter gene activity [56]. Analysis of the ability of a series of cucuminoids to induce quinone reductase (QR) activity in Hepa1c1c7 cells revealed that the introduction of aromatic 0 -hydroxy groups into the curcuminoid skeleton raises the inducer potency more than 30-fold [82]. According to this study, demethoxycurcumin and bis-demethoxycurcumin exhibited almost similar capability to induce QR activity as compared to that observed with curcumin [82]. However, demethoxycurcumin and bis-demethoxycurcumin induced HO-1, GCL and NQO-1 mRNA expression and $\mathrm{HO}-1$ promoter activity, and activated Nrf2 more effectively than curcumin in mouse pancreatic-beta (MIN6) cells [53].

\section{Epigallocatechin gallate (EGCG)}

EGCG, the major active catechin component of green tea, has been known to possess anti-oxidant, anti-inflammatory and chemopreventive properties [83], [84]. EGCG was found to be the most potent Nrf2 activator among the green tea polyphenols, as evidenced by its pronounced ability to induce ARE-luciferase reporter gene transactivation [85]. EGCG has been reported to activate Nrf2 and induce expression of $\mathrm{HO}-1$ in endothelial cells [50] and B-lymphoblasts [49]. While EGCG-induced HO-1 expression was attributed to activation of Akt and ERK1/2 in endothelial cells [50], p38 MAP kinase as well as Akt is involved in HO-1 induction and Nrf2 nuclear translocation in B lympoblasts treated with EGCG [49]. We also observed that EGCG induced ac- 
tivation of ERK1/2 and Akt through phosphorylation in cultured human mammary epithelial MCF-10A cells. The pharmacological inhibitors of MEK and PI3K, which are upstream kinases responsible for phosphorylation of ERK1/2 and Akt, respectively, attenuated the nuclear localization of Nrf2 induced by EGCG [51]. Similarly, a nontoxic dose of EGCG increased the ARE-luciferase activity and the expression of ARE-regulated genes in HepG2 cells by activating MAP kinases [85].

EGCG inhibited the growth and liver/pulmonary metastasis of colon tumor implanted orthotopically in the cecum of nude mice, and this anticancer effect was proposed to be partly mediated by activating the Nrf2-UGT1A signal pathway [86]. C57BL/ $6 \mathrm{~J}$ and $\mathrm{C} 57 \mathrm{BL} / 6 \mathrm{~J} / \mathrm{nrf2}(-/-)$ mice were given an oral dose of EGCG at $200 \mathrm{mg} / \mathrm{kg}$ or treated with vehicle. Both liver and small intestine were collected $3 \mathrm{~h}$ and $12 \mathrm{~h}$ after treatment, and global gene expression profiles were compared [87]. Genes that were either induced or suppressed more than two-fold by EGCG treatment compared with vehicle treatment in the same genotype group were filtered using the GeneSpring software. Among these well-defined genes, 671 EGCG-regulated Nrf2-dependent genes and 256 EGCG-regulated Nrf2-independent genes were identified in liver, whereas 228 EGCG-regulated Nrf2-dependent genes and 98 EGCG-regulated Nrf2-independent genes were identified in the small intestine [87].

\section{Allyl sulfides}

Garlic oil contains several organosulfur compounds, such as diallyl sulfide (DAS), diallyl disulfide (DADS), and diallyl trisulfide (DATS), capable of inducing carcinogen-detoxifying enzymes. DAS induced NQO1 by 5 -fold in wild-type mice, whereas induction was completely absent in $\operatorname{nrf2}(-/-)$ mice, indicating that DAS also activates Nrf2 [88]. DAS induced a dose- and time-dependent increase of HO-1 protein and mRNA levels without provoking apparent toxicity in HepG2 cells [89]. Furthermore, protein expression, nuclear translocation, and DNAbinding activity of Nrf2 were induced by DAS treatment. Both ERK and p38 MAP kinase pathways appeared to play an important role in DAS-induced Nrf2 nuclear translocation and HO-1 gene expression [89]. DAS caused a transient increase of ROS. The thiol antioxidant $N$-acetyl---cysteine (NAC) blocked not only DAS-induced ROS production but also ERK activation as well as nuclear translocation of Nrf2, and also HO-1 expression. Likewise, the prototypic antioxidant enzyme catalase attenuated DAS-induced ERK activation, Nrf2 nuclear translocation and HO-1 protein induction, whereas Trolox was ineffective. DAS-treatment rendered the HepG2 cells resistant to oxidative stress caused by hydrogen peroxide or arachidonic acid, and this was attributable to its induction of $\mathrm{HO}-1$ as pharmacologic inhibition of HO- 1 activity blunted the cytoprotective effects of DAS [89]. It is noteworthy that the prooxidant activity of DAS contributes to Nrf2-driven antioxidant enzyme induction, which conferred the protection against oxidative cell death induced by external stimuli.

Chen et al. examined Nrf2-driven ARE activity and antioxidant gene expression by garlic organosulfur compounds in HepG2 cells [90]. Among the three allyl sulfides derived from garlic, DATS was most potent in terms of inducing ARE activation and expression of detoxifying enzymes, such as HO- 1 and NQO1. Cotreatment with thiol antioxidants NAC and GSH abrogated the ARE activity and the Nrf2 accumulation induced by DATS. Three major MAP kinases, i.e., ERK, JNK, and p38, were activated by DATS treatment. However, the inhibition of these MAP kinases did not affect DATS-induced ARE activity. Likewise, the PKC pathway was not directly involved in DATS-induced ARE activity, but instead the calcium-dependent signaling pathway appeared to play a role in the DATS-induced [90].

\section{Resveratrol}

Resveratrol (trans-3,5,4'-trihydroxystilbene) is another extensively investigated dietary chemopreventive phytochemical that is present in grapes and other plant species. Resveratrol exerts anti-oxidant, anti-inflammatory and chemopreventive activities by modulating various events in cellular signaling [91]. Resveratrol prevented chemically induced tumorigenesis in many experimental models [92], [93], [94], [95]. As a mechanism of carcinogen detoxification and cellular antioxidant defense, resveratrol induced NQO1 activity in Hepa1c1c7 cells [96]. In another study, human K562 cells treated with resveratrol exhibited increased NQO1 expression that peaked at $24-48 \mathrm{~h}$ [97]. A 2.5-fold rise in NQO1 protein levels was associated with a comparable elevation in the mRNA copy number and a 3- to 5fold increase in NQO1 enzymatic activity. The stimulation of NQO1 gene expression by resveratrol involved the ARE signaling, accompanied by an increase in the state of phosphorylation of Nrf2 and its re-distribution to the nucleus [97]. The compound was found to induce HO-1 expression and activity in human aortic smooth muscle [98] and rat pheochromocytoma (PC12) cells [99] via activation of NF- $\kappa B$ and Nrf2, respectively.

Treatment of human primary small airway epithelial and human alveolar epithelial (A549) cells with cigarette smoke extract (CSE) dose-dependently decreased glutathione (GSH) levels and GCL activity, effects that were associated with enhanced production of ROS [100]. Resveratrol restored CSE-depleted GSH levels by upregulation of GCL via activation of Nrf2 and also quenched CSE-induced release of ROS. Interestingly, CSE hampered nuclear translocation of Nrf2 in A549 and small airway epithelial cells by sequestering Nrf2 in the cytosol through post-translational modifications of this transcription factor, such as aldehyde/carbonyl adduct formation and nitration. On the other hand, resveratrol attenuated CSE-mediated Nrf2 modifications, thereby inducing nuclear translocation of Nrf2 and GCL gene transcription [100].

\section{Pungent vanilloids}

The chemopreventive potential of capsaicin (trans-8-methyl- $\mathrm{N}$ vanillyl-6-nonenamide), a major pungent principle of hot chilli pepper (Capsicum annuum L., Solanaceae), has been reviewed earlier [101], [102]. Capsaicin induced expression of HO-1 in HepG2 cells by activating PI3K/Akt-mediated activation of Nrf2 signaling in a ROS-dependent manner [52]. This study hypothesized that a quinone metabolite or other reactive forms of capsaicin would covalently modify NQO1, thereby suppressing the expression and activity of this antioxidant enzyme. The resulting overproduction of ROS is speculated to stimulate PI3K/Aktmediated activation of Nrf2 [52]. (10)-Shogaol, a pungent ingredient of ginger (Zingiber officianale Roscoe, Zingiberaceae) has been reported to interact with the cysteine 151 residue of human Keap1 to form an alkylated adduct as detected by the FT-ICR mass spectrometer [103]. The alkylation of Keap1 by this electrophilic natural product may contribute to its antioxidant, anti-inflammatory and chemopreventive properties.

\section{Lycopene}

Lycopene, a natural antioxidant present predominantly in tomato products, has been reported to exert chemopreventive activi- 
ty, especially against prostate and mammary carcinogenesis. The antioxidant properties of lycopene are thought to be primarily responsible for its chemopreventive effects [104]. Ben-Dor et al. have demonstrated that treatment of MCF-7 cells, transiently transfected with GCS-hARE-tk-luc reporter plasmid, with lycopene increased the GCS-ARE activity [105]. GCS-ARE and NQO1ARE reporter activities were induced in HepG2 cells as well [105]. Lycopene elevated the mRNA and/or protein levels of GCS and NQO1, enhanced the cellular GSH level and reduced ROS generation in MCF-7 and HepG2 cells. Incubation of HepG2 cells with lycopene increased the nuclear translocation of Nrf2. In addition, the induction of NQO1 and GCS by lycopene was diminished in HepG2 cells ectopically expressing a dominant negative mutant Nrf2, suggesting that lycopene induced NQO1 and GCS via Nrf2 activation [105].

\section{Miscellaneous}

Epidemiological studies have revealed an inverse relationship between coffee consumption and the risk of certain types of cancer [106], [107], [108]. Dietary administration of coffee (3 or 6\%) for 5 days showed a several-fold increased expression of mRNA transcripts of NQO1 and GSTA- 1 in the liver and small intestine, and that of UGTA-6 and GCLC in the small intestine of $\mathrm{nrf2}^{+/+}$ mice as compared to $n r f 2^{-1-}$ animals [109]. The coffee-derived diterpenes, cafestol and kahweol, when treated to embryonic fibroblasts isolated from $\mathrm{nrf2}^{+/+}$mice, increased NQO1 mRNA expression to a greater extent than that achieved with embryonic fibroblasts from $n r f 2^{-l-}$ mice. This study also demonstrated that the induction of NQO1 mRNA expression was dependent on the presence of an ARE element at the gene promoter segment and that the coffee-specific diterpenes induced NQO1 reporter gene activity via the activation of Nrf2 [109].

Carnosol, an ortho-phenolic diterpene present in rosemary (Rosmarinus officinalis, Lamiaceae), induced HO-1 expression at both protein and mRNA levels by increasing the binding of Nrf2 to ARE and induced the Nrf2-dependent activation of $\mathrm{HO}-1$ promoter in PC12 cells via upregulation of ERK, p38 MAP kinase and JNK pathways [110]. Cinnamaldehyde present in the dried stem bark of Cinnamomum cassia Presl. (Lauraceae), induced HO-1 protein expression, increased Nrf2 nuclear translocation and the ARE-luciferase reporter activity in human endothelial cells [111].

Zerumbone, a chemopreventive sesquiterpene derived from tropical ginger (Zingiber zerumbet Smith) [112] enhanced the cellular GSH level and induced a battery of antioxidant enzymes, such as GSTP-1, GCL, GPx and HO-1 in normal rat liver epithelial (RL34) cells. Treatment of RL34 cells with zerumbone ( $25 \mu \mathrm{M})$ showed increased nuclear accumulation of Nrf2, while its reduced analogues such as $\alpha$-humulene or 8-hydroxy- $\alpha$-humulene failed to activate Nrf2 and induce aforementioned antioxidant enzymes, suggesting that the $\alpha, \beta$-carbonyl moiety at the 8 position is crucial for Nrf2 activation and antioxidant enzyme induction by zerumbone [113].

Chalcone, an $\alpha, \beta$-unsaturated flavonoid, upregulated the nuclear levels of Nrf2 and increased the ARE-luciferase activity and also the thioredoxin reductase promoter activity in bovine aortic endothelial cells [114]. It induced expression of thioredoxin reductase as well as HO-1 in the same cells. Furthermore, chalcone suppressed the activation of NF- $\kappa$ B and STAT3 in both IL-6 and LPS-stimulated endothelial cells. The presence of an $\alpha, \beta$-unsaturated carbonyl moiety is critical for the anti-inflammatory activity exerted by chalcone [114]. Some synthetic chalcone derivatives, such as 2',4',6'-tris(methoxymethoxy)chalcone and 3',4',5'3,4,5hexamethoxychalcone diminished NF- $\mathrm{kB}$ activation, whereas they induced HO-1 expression [115], [116]. The structure-activity relationship assay of a series of unsubstituted and hydroxy-substituted chalcones showed that ring hydroxylation at position C2 or $\mathrm{C} 2$ ' or $\mathrm{C}^{\prime}$ ' enhanced the phase 2 enzyme inducing ability by 2 - to 3-fold as compared to non-substituted chalcones or 4-hydroxysubstituted chalcone [117]. The simultaneous presence of a hydroxy moiety at C2 and C2' further incrased the potency [117]. Xanthohumol, a sesquiterpene derived from hops (Humulus lupulus L.), exhibited chemopreventive activity. One of the mechanisms of chemoprevention with xanthohumol was the induction of antioxidant enzymes. Pretreatment of hepa1c1c7 cells with xanthohumol diminished menadione-induced DNA damage via up-regulation of NQO1 [118]. Xanthohumol induced NQO1 in an ARE-dependent manner, partly via the activation of Nrf2 through alkylation of Keap1 at the cysteine 27 residue [118]. In addition, liquid chromatographic-tandem mass spectrometric (LC-MS/MS) analysis revealed that xanthohumol alkylated the cysteine 151 residue, located at the BTB domain of Keap1, thereby contributing to the Nrf2-dependent ARE activation [103]. Likewise, isoliquiritigenin derived from licorice has also been shown to alkylate the cysteine 151 residue of Keap-1, thereby inducing the ARE activity [103].

\section{Conclusion \\ $\nabla$}

Considering the burden of health-care cost as a major global concern, the dietary chemoprevention provides an inexpensive, readily applicable, and easily accessible approach to cancer control and management. In general, dietary phytochemicals exert their chemopreventive effects through multiple mechanisms. The saturation of cellular defense mechanisms due to overwhelming external stress or their disruption as a consequence of deregulated intracellular signaling pathways responsible for inducing expression of a battery of carcinogen detoxifying/antioxidant enzymes would make cells/tissues more vulnerable to oxidative, nitrosative and inflammatory insults implicated in multi-stage carcinogenesis. Therefore, fortification of cellular defense mechanism or restoration of stress-response signaling by intaking dietary phytonutrients provides an important strategy for chemoprevention.

The bZIP transcription factor Nrf2 controls the cellular signaling involved in the transcriptional activation of genes encoding a panel of phase 2 detoxifying/antioxidant enzymes and stress-responsive proteins. Nrf2 plays an essential role in maintaining cellular homeostasis and hence represents a critical target for chemoprevention of oxidative stress- or inflammation-associated carcinogenesis. Under normal physiological conditions, $\mathrm{Nrf2}$ forms an inactive complex with the negative regulator, Keap1 which controls the subcellular localization and steadystate levels of Nrf2. Cysteine residues present in Keap1 function as redox sensors, and oxidation or chemical modification of some of the highly reactive cysteine residues facilitates the dissociation of Nrf2 from Keap1 and subsequent nuclear translocation. Therefore Nrf2 constitutes a unique "redox switch" that can be turned on in response to redox imbalance caused by oxidative and electrophilic stresses. However, such adaptive response to external stress is normally transient and prone to be readily saturated. Therefore, it may be necessary to maintain proper levels of cellular defense capacity by inducing de novo synthesis of cy- 


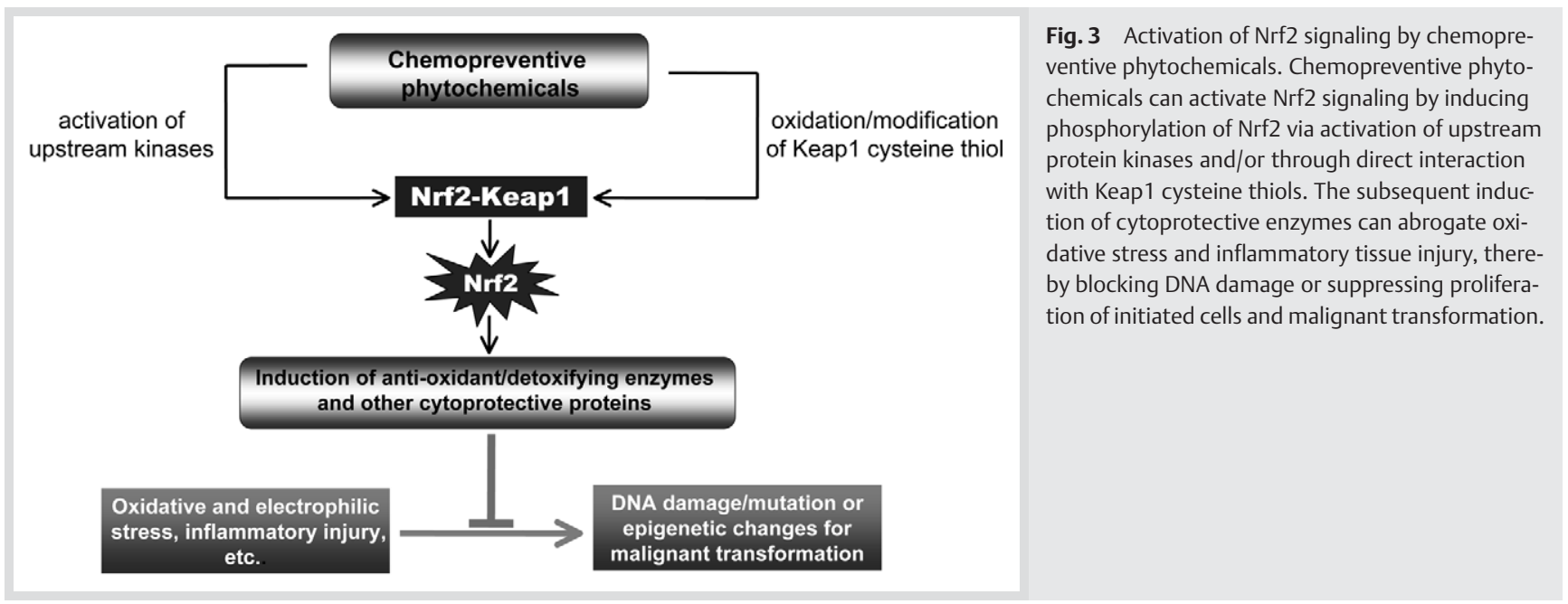

toprotective proteins in a more sustained manner. In this context, it is of particular interest to note that many inducers of phase 2 and antioxidant proteins are present in our daily diets, especially those derived from edible plants, and intake of these dietary phytochemicals enures long-term cytoprotection. While oxidation and/or direct modification of critical Keap1 cysteine thiols have been proposed as a major plausible mechanism underlying activation of Nrf2, phosphorylation of Nrf2 at specific serine and/or tyrosine residues also represents another important event in cytoprotective gene induction, which is modulated by many dietary chemopreventives. The activation of Nrf2-ARE signaling by dietary inducers will fortify cellular defense against oxidative, electrophilic and inflammatory stresses which are broadly implicated in multi-stage carcinogenesis as schematically represented in $\odot$ Fig. 3 .

\section{Acknowledgements \\ $\nabla$}

This work was supported by the Korea Science and Engineering Foundation for the National Research Laboratory Program and also for the Biogreen Project. Joydeb Kumar Kundu is supported by the BK21 Program through the Applied Pharmaceutical Life Sciences Research Division of Seoul National University.

\section{References}

1 Sporn MB, Dunlop NM, Newton DL, Smith JM. Prevention of chemical carcinogenesis by vitamin $A$ and its synthetic analogs (retinoids). Fed Proc 1976; 35: $1332-8$

2 Sporn MB. Approaches to prevention of epithelial cancer during the preneoplastic period. Cancer Res 1976; 36: 2699- 702

3 Wattenberg LW. Chemoprophylaxis of carcinogenesis: a review. Cancer Res 1966; 26: 1520-6

4 Wattenberg LW. Chemoprevention of cancer. Cancer Res 1985; 45: 1 8

5 Surh YJ. Cancer chemoprevention with dietary phytochemicals. Nat Rev Cancer 2003; 3: 768-80

6 Moolgavkar SH. The multistage theory of carcinogenesis and the age distribution of cancer in man. J Natl Cancer Inst 1978; 61: 49-52

7 Gius D, Spitz DR. Redox signaling in cancer biology. Antioxid Redox Signal 2006; 8: 1249-52

8 Chen C, Kong AN. Dietary chemopreventive compounds and ARE/EpRE signaling. Free Radic Biol Med 2004; 36: 1505 - 16

9 Lee JS, Surh YJ. Nrf2 as a novel molecular target for chemoprevention. Cancer Lett 2005; 224: $171-84$
10 Dinkova-Kostova AT, Talalay P. Direct and indirect antioxidant properties of inducers of cytoprotective proteins. Mol Nutr Food Res 2008; 52: $128-38$

11 Eggler AL, Gay KA, Mesecar AD. Molecular mechanisms of natural products in chemoprevention: Induction of cytoprotective enzymes by Nrf2. Mol Nutr Food Res 2008; 52: S84-94

12 Motohashi H, Yamamoto M. Nrf2-Keap1 defines a physiologically important stress response mechanism. Trends Mol Med 2004; 10: 549 57

13 Kwak MK, Wakabayashi N, Kensler TW. Chemoprevention through the Keap1-Nrf2 signaling pathway by phase 2 enzyme inducers. Mutat Res 2004; 555: 133 - 48

14 Ramos-Gomez M, Kwak MK, Dolan PM, Itoh K, Yamamoto M, Talalay P et al. Sensitivity to carcinogenesis is increased and chemoprotective efficacy of enzyme inducers is lost in nrf2 transcription factor-deficient mice. Proc Natl Acad Sci U S A 2001; 98: 3410-5

15 Chan K, Kan YW. Nrf2 is essential for protection against acute pulmonary injury in mice. Proc Natl Acad Sci U S A 1999; 96: 12731 -6

16 Ramos-Gomez M, Dolan PM, Itoh K, Yamamoto M, Kensler TW. Interactive effects of nrf2 genotype and oltipraz on benzo[ $a]$ pyrene-DNA adducts and tumor yield in mice. Carcinogenesis 2003; 24: 461 - 7

17 Fahey JW, Haristoy X, Dolan PM, Kensler TW, Scholtus I, Stephenson KK et al. Sulforaphane inhibits extracellular, intracellular, and antibioticresistant strains of Helicobacter pylori and prevents benzo[a]pyreneinduced stomach tumors. Proc Natl Acad Sci U S A 2002; 99: 7610-5

18 Rangasamy T, Guo J, Mitzner WA, Roman J, Singh A, Fryer AD et al. Disruption of Nrf2 enhances susceptibility to severe airway inflammation and asthma in mice. J Exp Med 2005; 202: 47-59

19 Thimmulappa RK, Scollick C, Traore K, Yates M, Trush MA, Liby KT et al. Nrf2-dependent protection from LPS induced inflammatory response and mortality by CDDO-imidazolide. Biochem Biophys Res Commun 2006; 351: $883-9$

20 Chen XL, Kunsch C. Induction of cytoprotective genes through Nrf2/antioxidant response element pathway: a new therapeutic approach for the treatment of inflammatory diseases. Curr Pharm Des 2004; 10: $879-91$

21 Khor TO, Huang MT, Kwon KH, Chan JY, Reddy BS, Kong AN. Nrf2-deficient mice have an increased susceptibility to dextran sulfate sodiuminduced colitis. Cancer Res 2006; 66: 11580-4

22 Zhang DD, Lo SC, Cross JV, Templeton DJ, Hannink M. Keap1 is a redoxregulated substrate adaptor protein for a Cul3-dependent ubiquitin ligase complex. Mol Cell Biol 2004; 24: 10941 - 53

23 Zhang DD, Lo SC, Sun Z, Habib GM, Lieberman MW, Hannink M. Ubiquitination of Keap1, a BTB-Kelch substrate adaptor protein for Cul3, targets Keap 1 for degradation by a proteasome-independent pathway. J Biol Chem 2005; 280: 30091 -9

24 Eggler AL, Liu G, Pezzuto JM, van Breemen RB, Mesecar AD. Modifying specific cysteines of the electrophile-sensing human Keap1 protein is insufficient to disrupt binding to the Nrf2 domain Neh2. Proc Natl Acad Sci U S A 2005; 102: $10070-5$

25 Yuan X, Pan Z, Shen G, Kim JH, YU S et al. Mechanism of action of isothiocyanates: the induction of ARE-regulated genes is associated with 
activation of ERK and JNK and the phosphorylation and nuclear translocation of Nrf2. Mol Cancer Ther 2006; 5: 1918-26

26 Lo SC, Li X, Henzl MT, Beamer LJ, Hannink M. Structure of the Keap1:Nrf2 interface provides mechanistic insight into Nrf2 signaling. EMBO J 2006; 25: 3605 - 17

27 Huang HC, Nguyen T, Pickett CB. Regulation of the antioxidant response element by protein kinase C-mediated phosphorylation of NF-E2-related factor 2. Proc Natl Acad Sci U S A 2000; 97: 12 475-80

28 Bloom DA, Jaiswal AK. Phosphorylation of Nrf2 at Ser40 by protein kinase $C$ in response to antioxidants leads to the release of Nrf2 from INrf2, but is not required for Nrf2 stabilization/accumulation in the nucleus and transcriptional activation of antioxidant response element-mediated $\mathrm{NAD}(\mathrm{P}) \mathrm{H}$ :quinone oxidoreductase-1 gene expression. J Biol Chem 2003; 278: 44675-82

29 Itoh K, Chiba T, Takahashi S, Ishii T, Igarashi K, Katoh Y et al. An Nrf2/ small Maf heterodimer mediates the induction of phase II detoxifying enzyme genes through antioxidant response elements. Biochem Biophys Res Commun 1997; 236: $313-22$

30 Surh YJ, Kundu JK, Na HK, Lee JS. Redox-sensitive transcription factors as prime targets for chemoprevention with anti-inflammatory and antioxidative phytochemicals. J Nutr 2005; 135: 2993S - 3001S

$31 \mathrm{Na} \mathrm{HK}$, Surh YJ. Transcriptional regulation via cysteine thiol modification: a novel molecular strategy for chemoprevention and cytoprotection. Mol Carcinog 2006; 45: 368-80

32 Surh YJ, Na HK. NF-kB and Nrf2 as prime targets for chemoprevention and cytoprotection with anti-inflammatory and antioxidant phytonutrients. Genes Nutr 2008; 2: 313-7

33 Lee-Hilz YY, Boerboom AM, Westphal AH, van Berkel WJH, Aarts JMMJG, Rietjens IMCM. Pro-oxidant activity of flavonoids induces EpRE-mediated gene expression. Chem Res Toxicol 2006; 19: 1499-505

34 Hong J, Smith TJ, Ho CT, August DA, Yang CS. Effects of purified green and black tea polyphenols on cyclooxygenase- and lipoxygenasedependent metabolism of arachidonic acid in human colon mucosa and colon tumor tissues. Biochem Pharmacol 2001; 62: 1175-83

35 Long LH, Clement MV, Halliwell B. Artifacts in cell culture: rapid generation of hydrogen peroxide on addition of (-)-epigallocatechin, (-)-epigallocatechin gallate, $(+)$-catechin, and quercetin to commonly used cell culture media. Biochem Biophys Res Commun 2000; 273: 50-3

36 Dinkova-Kostova AT, Holtzclaw WD, Cole RN, Itoh K, Wakabayashi $N$, Katoh $Y$ et al. Direct evidence that sulfhydryl groups of Keap1 are the sensors regulating induction of phase 2 enzymes that protect against carcinogens and oxidants. Proc Natl Acad Sci U S A 2002; 99: 11908 13

37 Bensasson RV, Zoete V, Dinkova-Kostova AT, Talalay P. Two-step mechanism of induction of the gene expression of a prototypic cancer-protective enzyme by diphenols. Chem Res Toxicol 2008; 21: 805-12

38 Hong F, Freeman ML, Liebler DC. Identification of sensor cysteines in human Keap 1 modified by the cancer chemopreventive agent sulforaphane. Chem Res Toxicol 2005; 18: 1917-26

39 Yamamoto T, Suzuki T, Kobayashi A, Wakabayashi J, Maher J, Motohashi $\mathrm{H}$ et al. Physiological significance of reactive cysteine residues of Keap1 in determining Nrf2 activity. Mol Cell Biol 2008; 28: 2758 - 70

40 Copple IM, Goldring CE, Kitteringham NR, Park BK. The Nrf2-Keap1 defence pathway: role in protection against drug-induced toxicity. Toxicology 2008; 246: $24-33$

41 Kobayashi M, Yamamoto M. Nrf2-Keap1 regulation of cellular defense mechanisms against electrophiles and reactive oxygen species. Adv Enzyme Regul 2006; 46: 113-40

42 Jain AK, Mahajan S, Jaiswal AK. Phosphorylation and dephosphorylation of tyrosine 141 regulate stability and degradation of INrf2: a novel mechanism in Nrf2 activation. J Biol Chem 2008; 283: 17712 - 20

43 Clements CM, McNally RS, Conti BJ, Mak TW, Ting JP. DJ-1, a cancer- and Parkinson's disease-associated protein, stabilizes the antioxidant transcriptional master regulator Nrf2. Proc Natl Acad Sci U S A 2006: 103: $15091-6$

44 Rojo AI, Sagarra MR, Cuadrado A. GSK-3beta down-regulates the transcription factor Nrf2 after oxidant damage: relevance to exposure of neuronal cells to oxidative stress. J Neurochem 2008; 105: 192-202

45 Huang HC, Nguyen T, Pickett CB. Phosphorylation of Nrf2 at Ser-40 by protein kinase $C$ regulates antioxidant response element-mediated transcription. J Biol Chem 2002; 277: $42769-74$

46 Apopa PL, He X, Ma Q. Phosphorylation of Nrf2 in the transcription activation domain by casein kinase 2 (CK2) is critical for the nuclear translocation and transcription activation function of Nrf2 in IMR-32 neuroblastoma cells. J Biochem Mol Toxicol 2008; 22: 63 - 76
47 Jain AK, Jaiswal AK. GSK-3beta acts upstream of Fyn kinase in regulation of nuclear export and degradation of NF-E2 related factor 2. J Biol Chem 2007; 282: $16502-10$

48 Salazar M, Rojo AI, Velasco D, de Sagarra RM, Cuadrado A. Glycogen synthase kinase-3beta inhibits the xenobiotic and antioxidant cell response by direct phosphorylation and nuclear exclusion of the transcription factor Nrf2. J Biol Chem 2006; 281: 14841 - 51

49 Andreadi CK, Howells LM, Atherfold PA, Manson MM. Involvement of Nrf2, p38, B-Raf, and nuclear factor-kappaB, but not phosphatidylinositol 3-kinase, in induction of hemeoxygenase-1 by dietary polyphenols. Mol Pharmacol 2006; 69: 1033-40

50 Wu CC, Hsu MC, Hsieh CW, Lin JB, Lai PH, Wung BS. Upregulation of heme oxygenase-1 by Epigallocatechin-3-gallate via the phosphatidylinositol 3-kinase/Akt and ERK pathways. Life Sci 2006; 78: 2889 97

51 Na HK, Kim EH, Jung JH, Lee HH, Hyun JW, Surh YJ. (-)-Epigallocatechin gallate induces Nrf2-mediated-antioxidant enzyme expression via activation of PI3K and ERK in human mammary epithelial cells. Arch Biochem Biophys 2008; 476: $171-7$

52 Joung EJ, Li MH, Lee HG, Somparn N, Jung YS, Na HK et al. Capsaicin induces heme oxygenase-1 expression in HepG2 cells via activation of PI3K-Nrf2 signaling: NAD(P)H:quinone oxidoreductase as a potential target. Antioxid Redox Signal 2007; 9: 2087-98

53 Pugazhenthi S, Akhov L, Selvaraj G, Wang M, Alam J. Regulation of heme oxygenase- 1 expression by demethoxy curcuminoids through Nrf2 by a PI3-kinase/Akt-mediated pathway in mouse beta-cells. Am J Physiol Endocrinol Metab 2007; 293: E645 - 55

54 Kong AN, Owuor E, Yu R, Hebbar V, Chen C, Hu R et al. Induction of xenobiotic enzymes by the MAP kinase pathway and the antioxidant or electrophile response element (ARE/EpRE). Drug Metab Rev 2001; 33: $255-71$

55 Fahey JW, Zhang Y, Talalay P. Broccoli sprouts: an exceptionally rich source of inducers of enzymes that protect against chemical carcinogens. Proc Natl Acad Sci U S A 1997; 94: $10367-72$

56 Banning A, Deubel S, Kluth D, Zhou Z, Brigelius-Flohe R. The GI-GPx gene is a target for Nrf2. Mol Cell Biol 2005; 25: 4914-23

57 Brigelius-Flohe R, Banning A. Part of the series: from dietary antioxidants to regulators in cellular signaling and gene regulation. Sulforaphane and selenium, partners in adaptive response and prevention of cancer. Free Radic Res 2006; 40: 775-87

58 Shinkai Y, Sumi D, Fukami I, Ishii T, Kumagai Y. Sulforaphane, an activator of Nrf2, suppresses cellular accumulation of arsenic and its cytotoxicity in primary mouse hepatocytes. FEBS Lett 2006; 580: 1771 - 4

59 Wang XJ, Sun Z, Chen W, Eblin KE, Gandolfi JA, Zhang DD. Nrf2 protects human bladder urothelial cells from arsenite and monomethylarsonous acid toxicity. Toxicol Appl Pharmacol 2007; 225: 206-13

60 Thimmulappa RK, Mai KH, Srisuma S, Kensler TW, Yamamoto M, Biswal $S$. Identification of Nrf2-regulated genes induced by the chemopreventive agent sulforaphane by oligonucleotide microarray. Cancer Res 2002; 62: 5196-203

$61 \mathrm{Hu} R, \mathrm{Xu}$ C, Shen G, Jain MR, Khor TO, Gopalkrishnan A et al. Gene expression profiles induced by cancer chemopreventive isothiocyanate sulforaphane in the liver of C57BL/6 J mice and C57BL/6J/Nrf2 (-/-) mice. Cancer Lett 2006; 243: 170-92

62 Xu C, Huang MT, Shen G, Yuan X, Lin W, Khor TO et al. Inhibition of 7,12dimethylbenz $[a]$ anthracene-induced skin tumorigenesis in C57BL/ 6 mice by sulforaphane is mediated by nuclear factor E2-related factor 2. Cancer Res 2006; 66: 8293-6

63 Juge N, Mithen RF, Traka M. Molecular basis for chemoprevention by sulforaphane: a comprehensive review. Cell Mol Life Sci 2007; 64: $1105-27$

$64 \mathrm{Yu}$ R, Lei W, Mandlekar S, Weber MJ, Der CJ, Wu J et al. Role of a mitogen-activated protein kinase pathway in the induction of phase II detoxifying enzymes by chemicals. J Biol Chem 1999; 274: 27545 - 52

65 Jakubikova J, Sedlak J, Mithen R, Bao Y. Role of PI3K/Akt and MEK/ERK signaling pathways in sulforaphane- and erucin-induced phase II enzymes and MRP2 transcription, G2/M arrest and cell death in Caco-2 cells. Biochem Pharmacol 2005; 69: 1543 - 52

66 Manandhar S, Cho JM, Kim JA, Kensler TW, Kwak MK. Induction of Nrf2regulated genes by $3 \mathrm{H}-1,2$-dithiole-3-thione through the ERK signaling pathway in murine keratinocytes. Eur J Pharmacol 2007; 577: 17 27

67 Keum YS, Yu S, Chang PP, Yuan X, Kim JH, u C et al. Mechanism of action of sulforaphane: inhibition of p38 mitogen-activated protein kinase isoforms contributing to the induction of antioxidant response ele- 
ment-mediated heme oxygenase-1 in human hepatoma HepG2 cells. Cancer Res 2006; 66: 8804-13

68 Kwak MK, Cho JM, Huang B, Shin S, Kensler TW. Role of increased expression of the proteasome in the protective effects of sulforaphane against hydrogen peroxide-mediated cytotoxicity in murine neuroblastoma cells. Free Radic Biol Med 2007; 43: 809-17

69 Morimitsu Y, Nakagawa Y, Hayashi K, Fujii H, Kumagai T, Nakamura Y et al. A sulforaphane analogue that potently activates the Nrf2-dependent detoxification pathway. J Biol Chem 2002; 277: 3456 -63

70 Surh YJ, Chun KS. Cancer chemopreventive effects of curcumin. Adv Exp Med Biol 2007; 595: 149-72

71 Thangapazham RL, Sharma A, Maheshwari RK. Multiple molecular targets in cancer chemoprevention by curcumin. AAPS J 2006; 8: E443 - 9

72 Shen G, Xu C, Hu R, Jain MH, Gopalkrishnan A, Nair S et al. Modulation of nuclear factor E2-related factor 2-mediated gene expression in mice liver and small intestine by cancer chemopreventive agent curcumin. Mol Cancer Ther 2006; 5: 39-51

73 Garg R, Gupta S, Maru G. Dietary curcumin modulates transcriptional regulator(s) of phase I and phase II enzymes in benzo[a]pyrene-treated mice: mechanism of its anti-initiating action. Carcinogenesis 2008; 29: $1022-32$

74 Balogun E, Hoque M, Gong P, Killeen E, Green CJ, Foresti R et al. Curcumin activates the haem oxygenase-1 gene via regulation of Nrf2 and the antioxidant-responsive element. Biochem J 2003; 371: 887 - 95

75 Dickinson DA, Iles KE, Zhang H, Blank V, Forman HJ. Curcumin alters EpRE and AP-1 binding complexes and elevates glutamate-cysteine ligase gene expression. FASEB J 2003; 17: $473-5$

76 Nishinaka T, Ichijo $Y$, Ito M, Kimura M, Katsuyama M, Iwata K et al. Curcumin activates human glutathione S-transferase P1 expression through antioxidant response element. Toxicol Lett 2007; 170: 238 47

77 Rushworth SA, Ogborne RM, Charalambos CA, O'Connell MA. Role of protein kinase $C$ delta in curcumin-induced antioxidant response element-mediated gene expression in human monocytes. Biochem Biophys Res Commun 2006; 341: 1007-16

78 McNally SJ, Harrison EM, Ross JA, Garden OJ, Wigmore SJ. Curcumin induces heme oxygenase 1 through generation of reactive oxygen species, p38 activation and phosphatase inhibition. Int J Mol Med 2007; 19: $165-72$

79 Farombi EO, Shrotriya S, Na HK, Kim SH, Surh YJ. Curcumin attenuates dimethylnitrosamine-induced liver injury in rats through Nrf2-mediated induction of heme oxygenase-1. Food Chem Toxicol 2008; 46: $1279-87$

80 Pae HO, Jeong GS, Jeong SO, Kim HS, Kim SA, Yoo SJ et al. Roles of heme oxygenase-1 in curcumin-induced growth inhibition in rat smooth muscle cells. Exp Mol Med 2007; 39: 267 - 77

81 Kang ES, Woo IS, Kim HJ, Eun SY, Paek KS, im HJ et al. Up-regulation of aldose reductase expression mediated by phosphatidylinositol 3-kinase/Akt and Nrf2 is involved in the protective effect of curcumin against oxidative damage. Free Radic Biol Med 2007; 43: 535 - 45

82 Dinkova-Kostova AT, Talalay P. Relation of structure of curcumin analogs to their potencies as inducers of Phase 2 detoxification enzymes. Carcinogenesis 1999; 20: 911 - 4

$83 \mathrm{Na} \mathrm{HK}$, Surh YJ. Intracellular signaling network as a prime chemopreventive target of (-)-epigallocatechin gallate. Mol Nutr Food Res 2006; 50: $152-9$

84 Park OJ, Surh YJ. Chemopreventive potential of epigallocatechin gallate and genistein: evidence from epidemiological and laboratory studies. Toxicol Lett 2004; 150: $43-56$

85 Chen $C, Y u$ R, Owuor ED, Kong AN. Activation of antioxidant-response element (ARE), mitogen-activated protein kinases (MAPKs) and caspases by major green tea polyphenol components during cell survival and death. Arch Pharm Res 2000; 23: 605-12

86 Yuan JH, Li YQ Yang XY. Inhibition of epigallocatechin gallate on orthotopic colon cancer by upregulating the Nrf2-UGT1A signal pathway in nude mice. Pharmacology 2007; 80: 269-78

87 Shen G, Xu C, Hu R, Jain MR, Nair S, Lin W et al. Comparison of (-)-epigallocatechin 3-gallate elicited liver and small intestine gene expression profiles between C57BL/6 J mice and C57BL/6J/Nrf2 (-/-) mice. Pharm Res 2005; 22: $1805-20$

88 Fisher CD, Augustine LM, Maher JM, Nelson DM, Slitt AL, Klaassen CD et al. Induction of drug-metabolizing enzymes by garlic and allyl sulfide compounds via activation of constitutive androstane receptor and nuclear factor E2-related factor 2. Drug Metab Dispos 2007; 35: 995 1000
89 Gong P, Hu B, Cederbaum AI. Diallyl sulfide induces heme oxygenase-1 through MAPK pathway. Arch Biochem Biophys 2004; 432: 252 - 60

90 Chen C, Pung D, Leong V, Hebbar V, Shen G, Nair S et al. Induction of detoxifying enzymes by garlic organosulfur compounds through transcription factor Nrf2: effect of chemical structure and stress signals. Free Radic Biol Med 2004; 37: 1578 - 90

91 Kundu JK, Surh YJ. Molecular basis of chemoprevention by resveratrol: NF-kappaB and AP-1 as potential targets. Mutat Res 2004; 555: $65-$ 80

92 Jang M, Cai L, Udeani GO, Slowing KV, Thomas CF, Beecher CW et al. Cancer chemopreventive activity of resveratrol, a natural product derived from grapes. Science 1997; 275: $218-20$

93 Aziz MH, Reagan-Shaw S, Wu J, Longley BJ, Ahmad N. Chemoprevention of skin cancer by grape constituent resveratrol: relevance to human disease? FASEB J 2005; 19: 1193 - 5

94 Banerjee S, Bueso-Ramos C, Aggarwal BB. Suppression of 7,12-dimethylbenz $[a]$ anthracene-induced mammary carcinogenesis in rats by resveratrol: role of nuclear factor-kappaB, cyclooxygenase 2 , and matrix metalloprotease 9. Cancer Res 2002; 62: 4945 - 54

95 Li ZG, Hong T, Shimada Y, Sato F, Maeda M, Komoto I et al. Suppression of $\mathrm{N}$-nitrosomethylbenzylamine (NMBA)-induced esophageal tumorigenesis in F344 rats by resveratrol. Carcinogenesis 2002; 23: $1531-6$

96 Gerhauser C, Klimo K, Heiss E, Neumann I, Gamal-Eldeen A, Knauft et al. Mechanism-based in vitro screening of potential cancer chemopreventive agents. Mutat Res 2003; 523-524: $163-72$

97 Hsieh TC, Lu X, Wang Z, Wu JM. Induction of quinone reductase NQO1 by resveratrol in human $\mathrm{K} 562$ cells involves the antioxidant response element ARE and is accompanied by nuclear translocation of transcription factor Nrf2. Med Chem 2006; 2: 275-85

98 Juan SH, Cheng TH, Lin HC, Chu YL, Lee WS. Mechanism of concentration-dependent induction of heme oxygenase- 1 by resveratrol in human aortic smooth muscle cells. Biochem Pharmacol 2005; 69: 41 -8

99 Chen CY, Jang JH, Li MH, Surh YJ. Resveratrol upregulates heme oxygenase-1 expression via activation of NF-E2-related factor 2 in PC12 cells. Biochem Biophys Res Commun 2005; 331: $993-1000$

100 Kode A, Rajendrasozhan S, Caito S, Yang SR, Megson IL, Rahman I. Resveratrol induces glutathione synthesis by activation of Nrf2 and protects against cigarette smoke-mediated oxidative stress in human lung epithelial cells. Am J Physiol Lung Cell Mol Physiol 2008; 294: L478-88

101 Surh YJ, Lee SS. Capsaicin, a double-edged sword: toxicity, metabolism, and chemopreventive potential. Life Sci 1995; 56: 1845- 55

102 Surh YJ, Lee E, Lee JM. Chemoprotective properties of some pungent ingredients present in red pepper and ginger. Mutat Res 1998; 402: 259-67

103 Luo Y, Eggler AL, Liu D, Liu G, Mesecar AD, Breemen RB. Sites of alkylation of human Keap 1 by natural chemoprevention agents. J Am Soc Mass Spectrom 2007; 18: 2226 - 32

104 Hwang ES, Bowen PE. Can the consumption of tomatoes or lycopene reduce cancer risk? Integr Cancer Ther 2002; 1: 121 - 32

105 Ben-Dor A, Steiner M, Gheber L, Danilenko M, Dubi N, Linnewiel K et al. Carotenoids activate the antioxidant response element transcription system. Mol Cancer Ther 2005; 4: 177-86

106 Michels KB, Willett WC, Fuchs CS, Giovannucci E. Coffee, tea, and caffeine consumption and incidence of colon and rectal cancer. J Natl Cancer Inst 2005; 97: 282 - 92

107 Larsson SC, Wolk A. Coffee consumption and risk of liver cancer: a meta-analysis. Gastroenterology 2007; 132: 1740-5

108 Luo J, Inoue M, Iwasaki M, Sasazuki S, Otani T, Ye W et al. Green tea and coffee intake and risk of pancreatic cancer in a large-scale, population-based cohort study in Japan (JPHC study). Eur J Cancer Prev 2007; 16: $542-8$

109 Higgins LG, Cavin C, Itoh K, Yamamoto M, Hayes JD. Induction of cancer chemopreventive enzymes by coffee is mediated by transcription factor Nrf2. Evidence that the coffee-specific diterpenes cafestol and kahweol confer protection against acrolein. Toxicol Appl Pharmacol 2008; 226: $328-37$

110 Martin D, Rojo AI, Salinas M, Dias R, Gallardo G, Alam J et al. Regulation of heme oxygenase-1 expression through the phosphatidylinositol 3kinase/Akt pathway and the Nrf2 transcription factor in response to the antioxidant phytochemical carnosol. J Biol Chem 2004; 279: 8919-29

111 Liao BC, Hsieh CW, Liu YC, Tzeng TT, Sun YW, Wung BS. Cinnamaldehyde inhibits the tumor necrosis factor-alpha-induced expression of 
cell adhesion molecules in endothelial cells by suppressing NF-kappaB activation: Effects upon IkappaB and Nrf2. Toxicol Appl Pharmacol 2008; 229: $161-71$

112 Murakami A, Tanaka T, Lee JY, Surh YJ, Kim HW, Kawabata K et al. Zerumbone, a sesquiterpene in subtropical ginger, suppresses skin tumor initiation and promotion stages in ICR mice. Int J Cancer 2004; 110: $481-90$

113 Nakamura Y, Yoshida C, Murakami A, Ohigashi H, Osawa T, Uchida K. Zerumbone, a tropical ginger sesquiterpene, activates phase II drug metabolizing enzymes. FEBS Lett 2004; 572: 245-50

114 Liu YC, Hsieh CW, Wu CC, Wung BS. Chalcone inhibits the activation of NF-kappaB and STAT3 in endothelial cells via endogenous electrophile. Life Sci 2007; 80: 1420 - 30

115 Lee SH, Sohn DH, Jin XY, Kim SW, Choi SC, Seo GS. 2',4',6'-Tris(methoxymethoxy)chalcone protects against trinitrobenzene sulfonic acid-induced colitis and blocks tumor necrosis factor-alpha-induced intestinal epithelial inflammation via heme oxygenase 1-dependent and independent pathways. Biochem Pharmacol 2007; 74: 870-80

116 Alcaraz MJ, Vicente AM, Araico A, Dominguez JN, Terencio MC, Ferrándiz ML. Role of nuclear factor-kappaB and heme oxygenase-1 in the mechanism of action of an anti-inflammatory chalcone derivative in RAW 264.7 cells. Br J Pharmacol 2004; 142: 1191 - 9

117 Dinkova-Kostova AT, Abeygunawardana C, Talalay P. Chemoprotective properties of phenylpropenoids, bis(benzylidene)cycloalkanones, and related Michael reaction acceptors: correlation of potencies as phase 2 enzyme inducers and radical scavengers. J Med Chem 1998; 41: 5287-96

118 Dietz BM, Kang YH, Liu G, Eggler AL, Yao P, Chadwick LR et al. Xanthohumol isolated from Humulus lupulus Inhibits menadione-induced DNA damage through induction of quinone reductase. Chem Res Toxicol 2005; 18: 1296-305

119 McMahon M, Itoh K, Yamamoto M, Chanas SA, Henderson CJ, McLellan LI et al. The Cap'n'Collar basic leucine zipper transcription factor Nrf2 (NF-E2 p45-related factor 2) controls both constitutive and inducible expression of intestinal detoxification and glutathione biosynthetic enzymes. Cancer Res 2001; 61: 3299-307

120 Kalayarasan S, Sriram N, Sureshkumar A, Sudhandiran G. Chromium (VI)-induced oxidative stress and apoptosis is reduced by garlic and its derivative $S$-allylcysteine through the activation of $\mathrm{Nrf2}$ in the hepatocytes of Wistar rats. J Appl Toxicol 2008; 28: 908-19

121 Yuan JH, Li YQ Yang XY. Protective effects of epigallocatechin gallate on colon preneoplastic lesion induced by 2 -amino-3-methylimidazo[4,5-f]quinoline in mice. Mol Med 2008; 14: 590-8
122 Choi BM, Kim SM, Park TK, Li G, Hong S, Park H et al. Piperine protects cisplatin-induced apoptosis via heme oxygenase-1 induction in auditory cells. J Nutr Biochem 2007; 18: 615-22

123 Hwang YP, Jeong HG. The coffee diterpene kahweol induces heme oxygenase-1 via the PI3K and p38/Nrf2 pathway to protect human dopaminergic neurons from 6-hydroxydopamine-derived oxidative stress. FEBS Lett 2008; 582: 2655-62

124 Song HJ, Shin CY, Oh TY, Sohn UD. The protective effect of eupatilin on indomethacin-induced cell damage in cultured feline ileal smooth muscle cells: Involvement of HO-1 and ERK. J Ethnopharmacol 2008; 118: 94 - 101

125 Lim JH, Park HS, Choi JK, Lee IS, Choi HJ. Isoorientin induces Nrf2 pathway-driven antioxidant response through phosphatidylinositol 3kinase signaling. Arch Pharm Res 2007; 30: $1590-8$

126 Hanneken A, Lin FF, Johnson J, Maher P. Flavonoids protect human retinal pigment epithelial cells from oxidative-stress-induced death. Invest Ophthalmol Vis Sci 2006; 47: $3164-77$

127 Tanigawa S, Fujii M, Hou DX. Action of Nrf2 and Keap1 in ARE-mediated NQO1 expression by quercetin. Free Radic Biol Med 2007; 42: $1690-703$

128 Yao P, Nussler A, Liu L, Hao L, Song F, Schirmeier A et al. Quercetin protects human hepatocytes from ethanol-derived oxidative stress by inducing heme oxygenase-1 via the MAPK/Nrf2 pathways. J Hepatol 2007; 47: $253-61$

129 Kluth D, Banning A, Paur I, Blomhoff R, Brigelius-Flohe R. Modulation of pregnane $X$ receptor- and electrophile responsive element-mediated gene expression by dietary polyphenolic compounds. Free Radic Biol Med 2007; 42: $315-25$

130 Kweon MH, In Park Y, Sung HC, Mukhtar H. The novel antioxidant 3$O$-caffeoyl-1-methylquinic acid induces Nrf2-dependent phase II detoxifying genes and alters intracellular glutathione redox. Free Radic Biol Med 2006; 40: 1349-61

131 Choi BM, Kim BR. Upregulation of heme oxygenase- 1 by brazilin via the phosphatidylinositol 3-kinase/Akt and ERK pathways and its protective effect against oxidative injury. Eur J Pharmacol 2008; 580: $12-8$

132 Zhang Y, Guan L, Wang X, Wen T, Xing J, Zhao J. Protection of chlorophyllin against oxidative damage by inducing HO-1 and NQO1 expression mediated by PI3K/Akt and Nrf2. Free Radic Res 2008; 42: $362-71$ 